Review

\title{
Meroterpenes from Marine Invertebrates: Structures, Occurrence, and Ecological Implications
}

\author{
Marialuisa Menna *, Concetta Imperatore, Filomena D'Aniello and Anna Aiello \\ The NeaNat Group, Dipartimento di Farmacia, Università degli Studi di Napoli Federico II, \\ Via D. Montesano 49, 80131 Napoli, Italy; E-Mails: cimperat@unina.it (C.I.); \\ filomena.daniello@unina.it (F.D.); aiello@unina.it (A.A.) \\ * Author to whom correspondence should be addressed; E-Mail: mlmenna@unina.it; \\ Tel.: +39-081-678-518; Fax: +39-081-678-552.
}

Received: 19 March 2013; in revised form: 7 April 2013 / Accepted: 7 May 2013 /

Published: 17 May 2013

\begin{abstract}
Meroterpenes are widely distributed among marine organisms; they are particularly abundant within brown algae, but other important sources include microorganisms and invertebrates. In the present review the structures and bioactivities of meroterpenes from marine invertebrates, mainly sponges and tunicates, are summarized. More than 300 molecules, often complex and with unique skeletons originating from intra- and inter-molecular cyclizations, and/or rearrangements, are illustrated. The reported syntheses are mentioned. The issue of a potential microbial link to their biosynthesis is also shortly outlined.
\end{abstract}

Keywords: meroterpenes; terpene quinone; terpene hydroquinone; sponges; ascidians; soft corals

\section{Introduction}

Quinones are ubiquitous in nature, occurring as secondary metabolites in many organisms; often they are molecules essential to life, being intimately related to the oxidative processes in cells [1]. Polyprenylated 1,4-benzoquinones and hydroquinones, such as ubiquinones, plastoquinones, and tocopherols, are widespread in plants and animals, in which they play important roles in electron transport, photosynthesis, and as antioxidants [1,2]. Terpene quinone/hydroquinone natural products differing from the above-mentioned groups frequently occur as secondary metabolites in many organisms; they form a class of complex metabolites, generally called meroterpenes, of mixed 
biosynthetic origin which are partially derived from terpenoids. In addition to their wide occurrence, meroterpenes display a huge range of structural diversity, with structures varying from simple compounds comprising a prenyl unit linked to the hydroquinone unit to unique architectural scaffolds, often linked with varied functionalities, arising from intra- and intermolecular ring closures and/or rearrangements of the terpene chains. Moreover, they display important biological activities, undoubtedly related to their most prominent chemical feature, that is their ability to undergo redox cycling to generate reactive oxygen species (ROS) which can damage cells [3,4].

In the marine environment, meroterpenes have been isolated mainly from brown algae and microorganisms, but another important source are marine invertebrates, mainly sponges and tunicates. The present review provides an update on the meroterpenes so far isolated from marine invertebrates; it describes the structures and biological activities of 300 natural products, thus highlighting the structural diversity generated in this class of natural products and their potential in drug discovery. The issue of a potential microbial link to their biosynthesis is also shortly outlined.

\section{Meroterpenes from Ascidians}

While the majority of metabolites isolated from ascidians are nitrogen-containing compounds (alkaloids or peptide related compounds), ascidians belonging to the genus Aplidium are known as a rich source of meroterpenes [5-7]. The first biologically active tunicate metabolite was indeed geranylhydroquinone (2), isolated from an Aplidium sp. and, successively, found in many others Aplidium species; it was shown to offer protection against leukemia and tumor development in test animals [8]. Several linear diprenylquinones/hydroquinones (compounds 1-17, Figure 1) have been then reported from diverse Aplidium species (A. multiplicatum [9], A. savigny [10], A. conicum [11], A. glabrum [12], A. scabellum [13], Aplidium spp. [14,15]); the majority of them possess a linear side chain of the geranyl type with rare examples of neryl derivative such as verapliquinone D (13), verapliquinone B (14), and glabruquinone B (15). A. californicum has been the source of the simple monoprenyl derivatives $\mathbf{1}$ and $\mathbf{9}$ which were identified as anticancer and antimutagenic agents [16]. Glabruquinone A (3-demethylubiquinone Q2, 11) is closely related to the ubiquinones, although lacking the methyl group in the quinoid moiety; it is not a cytotoxin but demonstrated good cancer preventive activity on JB6 Cl 41 cell transformation activated by epidermal growth factor (EGF). Structure-activity relationships studies on its synthetic analogs demonstrated that this activity depend on the length of the side chain and on the position of the methoxyl groups in the quinone part of the molecule [17]. In vivo, anticancer properties of $\mathbf{1 1}$ and its synthetic analogs, as well as the molecular mechanism of its action against tumor cells, have been examined; it was shown to inhibit the growth of the solid Ehrlich carcinoma in mice and to induce apoptosis in various human tumor cell lines [18]. Both 2-geranyl-6-methoxy-1,4-hydroquinone-4-sulfate (17) and the triprenylated (farnesyl) hydroquinone rossinone A (8) were found to be active in an anti-inflammatory assay, in vitro, with activated human peripheral blood neutrophils; they inhibit the superoxide production when either $N$-formyl-methionyl-leucyl-phenilalanine (fMLP) or phorbol myristate acetate (PMA) were used to activate the respiratory burst $[13,15]$. The monoprenylhydroquinone $\mathbf{1}$ and geranylhydroquinone $\mathbf{2}$ were also active in the same assay [15], indicating that prenyl quinones could indeed hold promise for the development of new anti-inflammatory agents. 
Figure 1. Quinones and hydroquinones linked with linear prenyl chains.<smiles>[R]c1cc(O)ccc1O</smiles><smiles>[R]C1=CC(=O)C([R])=C([R])C1=O</smiles>

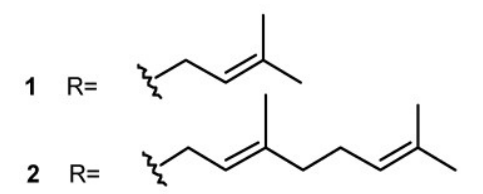<smiles>C/C(=C\CCC(C)(C)O)CCCC(C)(C)O</smiles><smiles>CCCCCC(C)(O)CCC=C(C)C</smiles><smiles>CCCC=CC(C)(O)CCC=C(C)C</smiles>

$6 \mathrm{R}=$<smiles>CC=CC(C)(C=CC)CCC=C(C)C</smiles>

$7 \mathrm{R}=$<smiles>C/C=C\C(C)(O)CCC=C(C)C</smiles>

$8 \mathrm{R}=$<smiles>CC/C=C(\C)CC/C=C(\C)C(=O)[C@H](O)C=C(C)C</smiles>

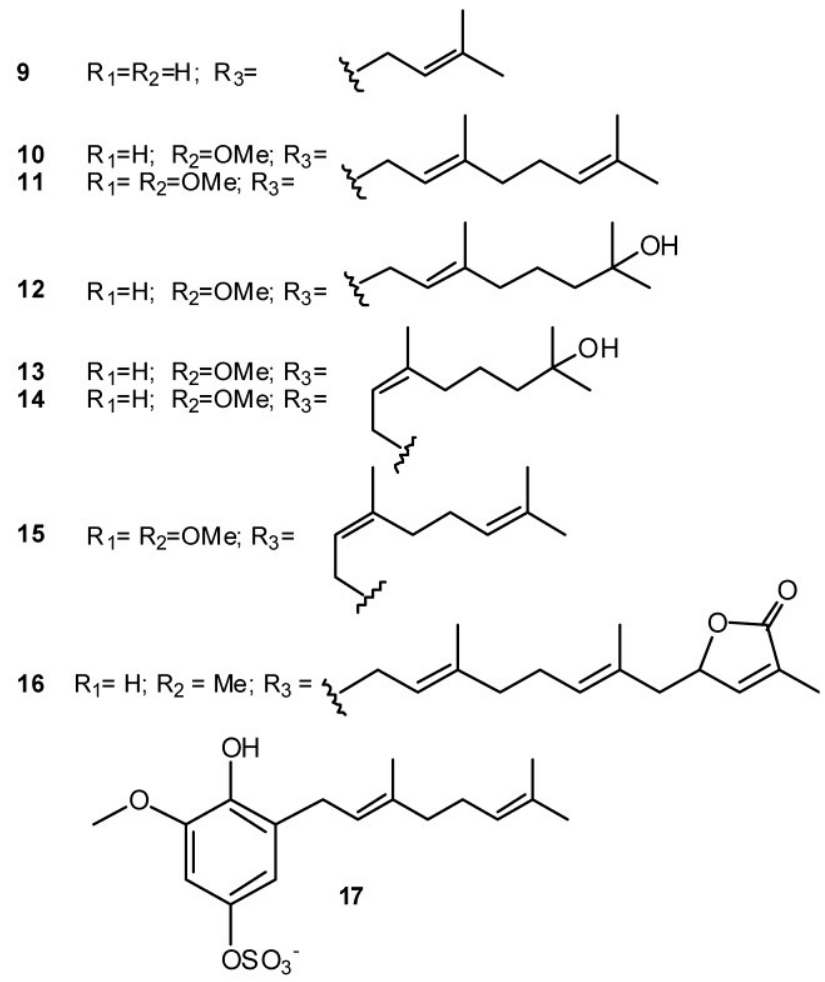

Several interesting classes of cyclic, polycyclic, macrocyclic, and/or dimeric prenyl quinones/hydroquinones are reported to occur in marine ascidians. The biosynthetic origin of these compounds has been largely speculated about; they clearly arise from corresponding derivatives with linear prenyl chains that are usually isolated concomitantly from the natural source. Ortho-prenylated quinones can undergo different chemical transformations, ranging from cascade cyclization reactions involving carbocation species [19] to pericyclic reactions, such as electrocyclizations or cycloadditions, via ortho-quinones methide intermediates [20]. However, with the data available, it is not possible to argue whether the above mentioned transformations occur in the organism, prior to its extraction, either enzymatically (in nature dehydrogenase enzymes appear to catalyze such processes [21]) or not, or that they take place during isolation and/or chromatographic purification.

Cyclodiprenyl hydroquinones/quinones (Figure 2) have been isolated from A. aff. densum (methoxyconidiol, 18) [22] and from A. conicum (conitriol, 19, and conidione, 20) [11]. Methoxyconidiol (18) displayed an antimitotic action on the first division of sea urchin embryos, disrupting M-phase progression and completely blocking cytokinesis without having any effect on DNA replication [23]. 
Figure 2. Cyclodiprenyl hydroquinones/quinones.

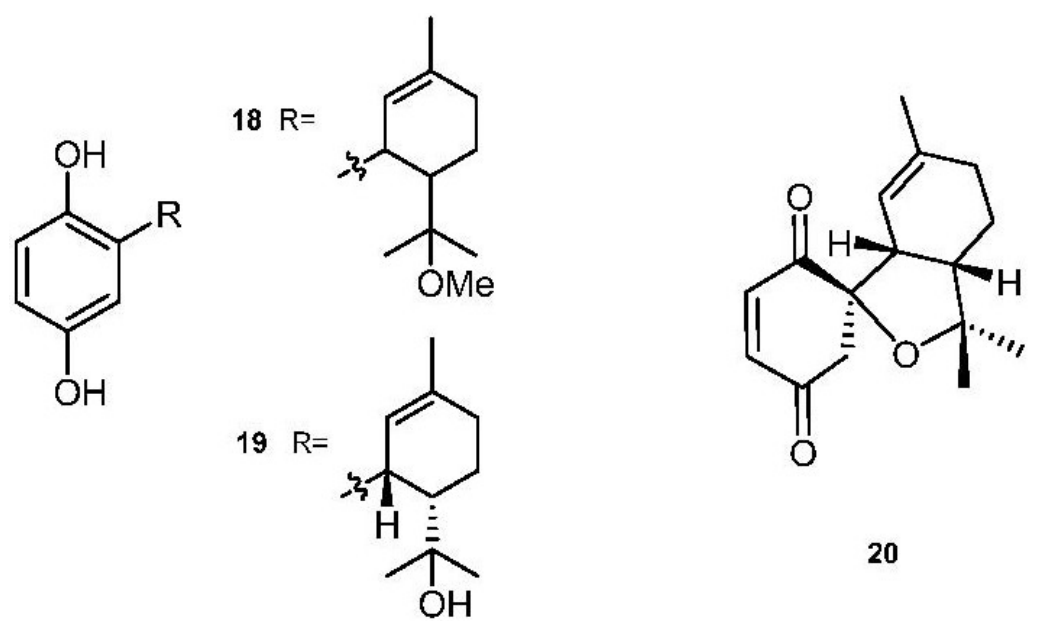

The occurrence of chromene ( $2 H$-benzopyran) derivatives as natural products has been reported in A. californicum (21) [14], A. costellatum (22) [24], A. multiplicatum (23) [9], A. scabellum (24) [13], and A. solidum (25 and 26) [25]. The chromane derivative 27 has been isolated from Synoicum costellatum [26], a species closely allied to the genus Aplidium, and successively found in A. conicum together with its C-1' epimer, conicol (28) [11]. Didehydroconicol (29) has been isolated from A. aff. densum [22]. Tuberatolides (30 and 31) and sargachromenols (32 and 33), isolated from Botryllus tuberatus along with their putative linear precursor yezoquinolide (16), antagonized the chenodeoxycholic acid (CDCA)-activated human farnesoid $\mathrm{X}$ receptor ( $\mathrm{hFXR}$ ), a ligand-dependent transcription factor in the nuclear receptor superfamily which has been recently identified as a promising drug target in the treatment of atherosclerosis [27]. Longithorol E (34), from A. longithorax, is a unique macrocyclic chromenol containing a new 14 membered carbocycle [28] (Figure 3).

Figure 3. Chromene (2H-benzopyran) derivatives.<smiles>[R]c1c(O)cc2c(c1[R])OC([R])(C)C=C2</smiles><smiles>[R7]C1([R])C=Cc2cc(O)cc(C)c2O1</smiles>
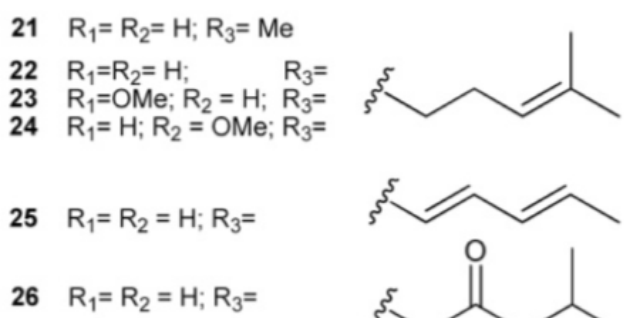

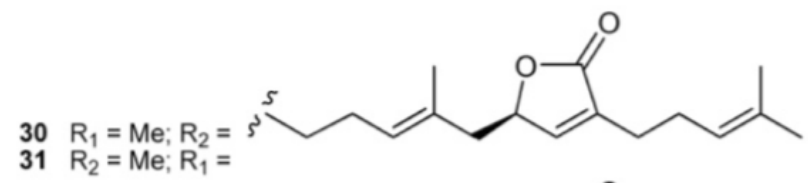
$31 \mathrm{R}_{2}=\mathrm{Me} ; \mathrm{R}_{1}=$<smiles>CC=CC=CCCCCC(=O)CC(C)C</smiles><smiles></smiles><smiles>CC1=CC2c3cc(O)ccc3OC(C)(C)[C@H]2CC1</smiles><smiles>Cc1ccc2c(c1)-c1cc(O)ccc1OC2(C)C</smiles><smiles>C/C1=C/CC/C(C)=C/CC2(C)C=Cc3cc(O)c(cc3O2)CC1</smiles> 
Rossinone B (35) is a triprenylated (farnesyl) quinone first isolated from an Antarctic Aplidium sp. [15] and successively recovered in the viscera extract of $A$. fugiense, also collected in Antarctica, along with the related compounds 36-38 [29] (Figure 4). Rossinone B has a rather novel structural architecture featured by a linearly fused 6-6-5-ring core, which so far has been found in only three plant-derived natural products, pycnanthuquinones A-C [19,30]. The tricyclic framework of $\mathbf{3 5}$ supposedly derive from the corresponding linear hydroquinone derivative rossinone A (8) which has been reported to co-occurr in Aplidium sp. [15]. Interestingly, neither acyclic hydroquinones nor putative quinone-containing precursors of compounds 35-38 were detected in A. fugiense extract [29]. Rossinone B (35) exhibited anti-inflammatory, antiviral, and antimicrobial activities [15]. Attracted by its novel chemical structure, promising biological properties and potentially intriguing biosynthetic pathway, a biomimetic total synthesis of $( \pm)$-rossinone $B$ has been achieved through a highly efficient strategy featuring a series of rationally designed reactions, including an intramolecular vinyl quinone Diels-Alder reaction to construct the linear 6-6-5 tricyclic core of 35 [31].

Figure 4. Cyclic triprenylated quinone/hydroquinones.

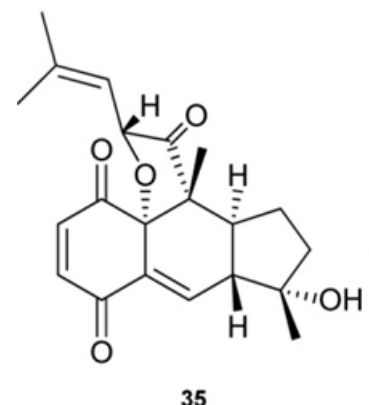

35

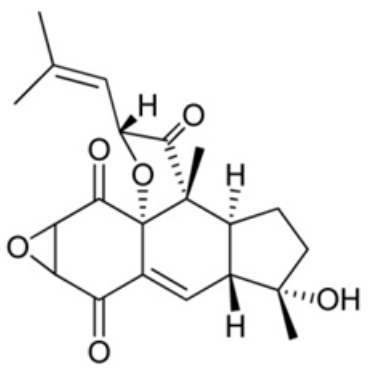

36

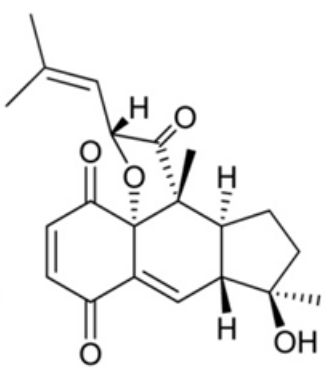

37

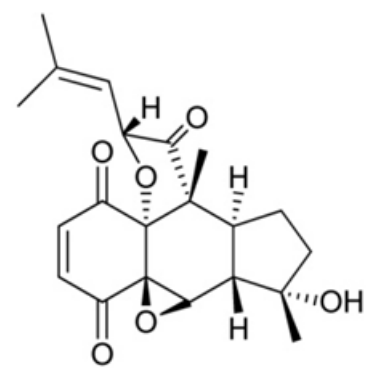

38

A. longithorax has been the source of longithorones and longithorols, a group of farnesylated quinone/hyroquinones featuring unprecedented macrocylic skeletons derived formally by the rarely encountered cyclization of farnesyl quinones/hydroquinones to give [9]- and [10]metacyclophane, as well as [12]paracyclophane structures [28,32-35]. Longithorones B-D (39-41), J (42), and K (43) together with longithorols $\mathrm{C}(\mathbf{4 4})$ and $\mathrm{D}(\mathbf{4 5})$, are monomeric $\mathrm{C}_{21}$ compounds (Figure 5). Longithorol $\mathrm{C}$ (44) could undergo an intramolecular cyclization, followed by dehydration, to yield the chromenol longithorol E (34), which is possibly an artifact of the isolation process. A short synthetic approach to the macrocyclic framework of longithorone $\mathrm{C}$ has been described via ring-closing metathesis using the Grubbs second generation catalyst [36]. Longithorone $J$ (42) is the first example of a $\gamma$-hydroxy-cyclohexenone in this class of compounds. Floresolides A-C (46-48) are three further monomeric cyclofarnesylated hydroquinones isolated from an Indonesian Aplidium sp. They are unique members of the longithorone/longithorol class of meroterpenes, having an endocyclic $\varepsilon$-lactone bridging the aromatic ring and a [10]metacyclophane moiety. Floresolides showed moderate cytotoxicity against KB cells [37]. 
Figure 5. Monomeric meta- and paracyclophane type meroterpenes.
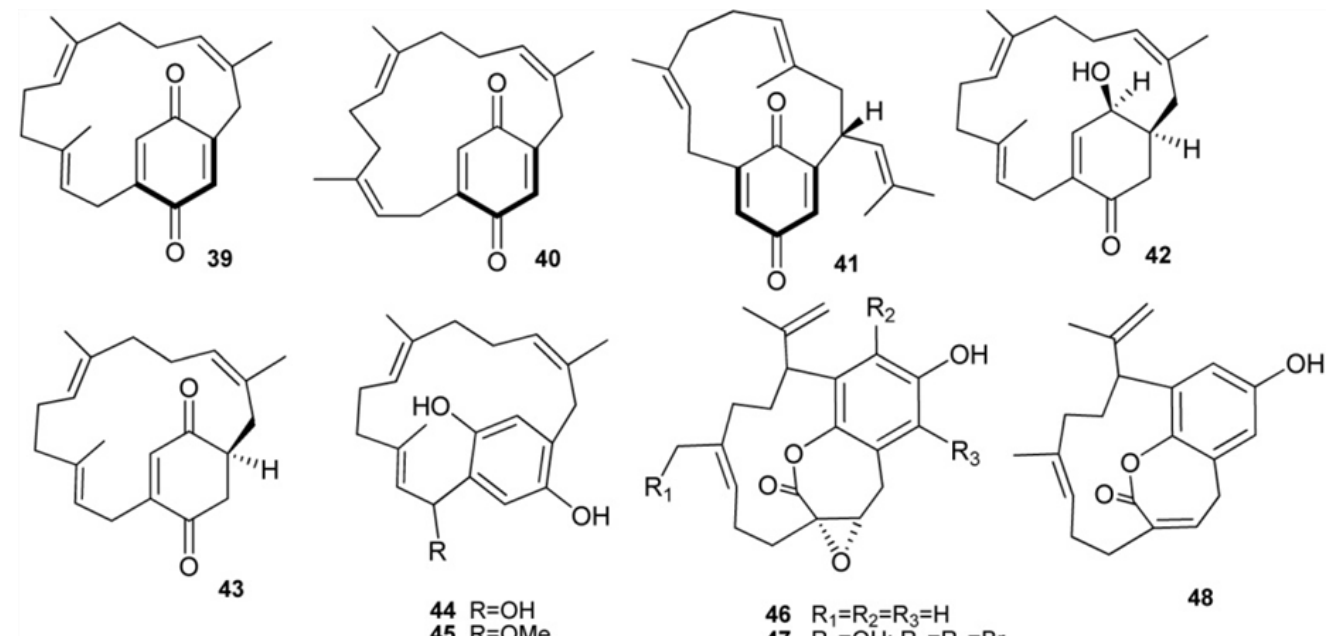

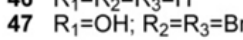

Longithorones A (49) and E-I (50-54) are dimeric compounds (Figure 6). Compounds 49-54, as well as the monomeric longithorones 39-43, exhibit atropisomerism arising from hindered rotation of quinone ring through their macrocyclic rings. The biosynthesis of dimeric longithorones, which have been supposed to originate by both intra- and intermolecular Diels-Alder reactions, has been speculated about. Fusion of the two farnesyl-quinone units can be envisioned as arising via a Diels-Alder cycloaddition of suitably unsaturated precursors, whereas rings $\mathrm{B}$ and $\mathrm{C}$ could arise by a transannular Diels-Alder reaction. The co-isolation of the monomers 39-43 provides some support for this proposal. The stereochemistry of the central carbocyclic rings in 35 and 39-43 is consistent with such a fusion [34]. An enantioselective biomimetic synthesis of longithorone A has been accomplished, which demonstrates the feasibility of the reactions proposed for the biosynthesis-albeit using non-enzymatic conditions. The challenge of a synthesis of longithorone A was heightened by the presence of two forms of chirality: the stereogenic centers present in the tricyclic core portion of the molecule and atropisomerism. The synthesis presents a unique example of chirality transfer in complex molecule synthesis involving the use of stereogenic centers to control atropisomerism, removal of the stereogenic centers, and transfer of the atropisomerism back to stereogenic centers in the natural product [38]. Longithorols A (55) and B (56) represent the first examples of hydroquinones in the [12]paracyclophane structure class. They were isolated as their pentaacetates because of their rapid decomposition occurring under purification conditions [35]. To date, the only biological activity reported for longithorones/longithorols class of marine metabolites pertains to longithorone A (49), which was shown to display cytotoxicity against P388 murine leukaemia cells.

Further examples of pseudodimeric meroterpenoids are scabellones A-D, (57-60) isolated from A. scabellum [13], possessing a benzo[c]chromene-7,10-dione scaffold particularly rare among natural products (Figure 7). Scabellone B (58) was found to inhibit the superoxide production by PMA-stimulated human neutrophils in vitro; it was also evaluated against the neglected disease parasites targets Trypanosoma brucei rhodesiense, T. cruzi, Leishmania donovani, and Plasmodium falciparum and exhibited selectivity toward Plasmodium falciparum (K1 chloroquine-resistant strain) with $\mathrm{IC}_{50} 4.8 \mu \mathrm{M}$ and only poor cytotoxicity (L6 rat myoblast cell line, $\mathrm{IC}_{50} 65 \mu \mathrm{M}$ ) [13]. 
Figure 6. Dimeric paracyclophane type meroterpenes.
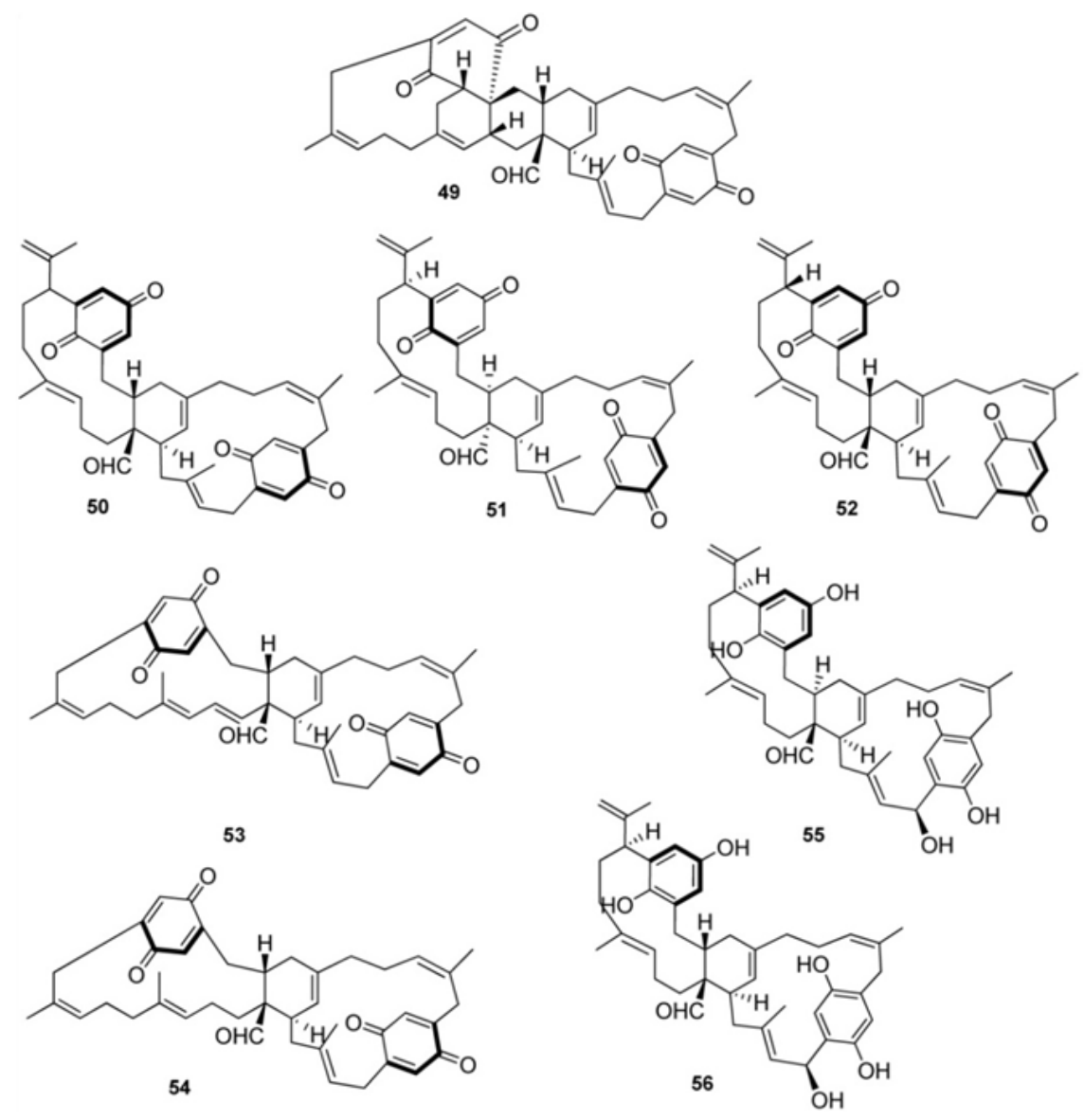

Figure 7. Dimeric benzo[c]chromene-7,10-dione containing meroterpenes.
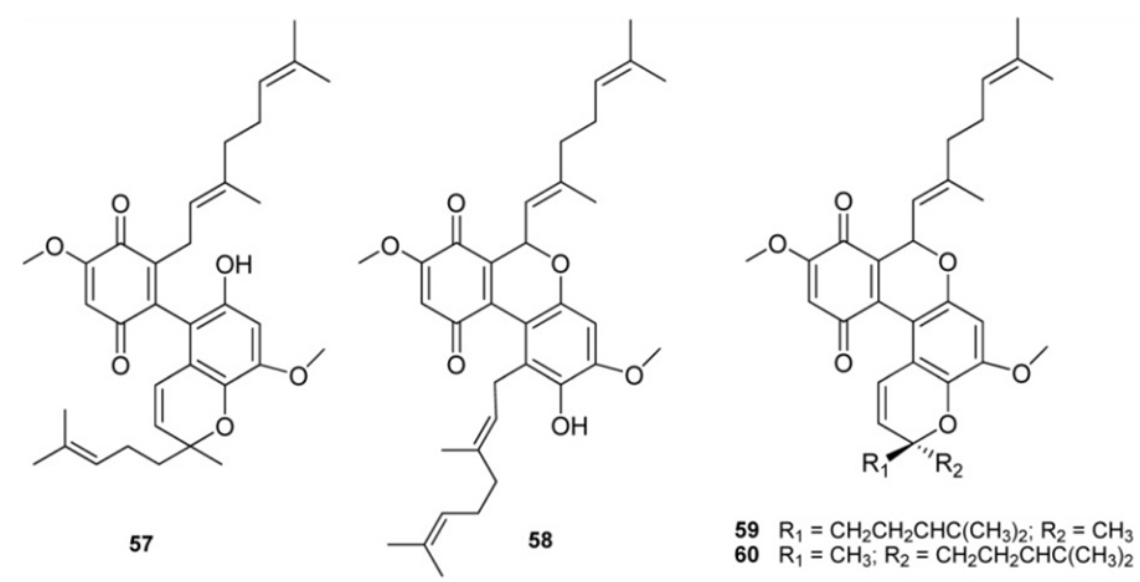

A sample of $A$. conicum collected along Sardinia coasts gave rise to the isolation of a large group of unique prenylated thiazinoquinones, namely conicaquinones A and B (61 and 62) [39], aplidinones A-C (63-65) [40], and thiaplidiaquinones A and B (66 and 67) [41] (Figure 8). All these meroterpenes feature an unusual 1,1-dioxo-1,4-thiazine ring fused with the quinone portion. Aplidinones $\mathrm{A}-\mathrm{C}(\mathbf{6 3}-\mathbf{6 5})$ and conicaquinones $\mathrm{A}$ and $\mathrm{B}(61$ and 62) possess a benzoquinones and a naphtoquinone moiety, respectively. Thiaplidiaquinones A and B (66 and 67) possess an unprecedented tetracyclic core, visibly composed of two geranylated benzoquinones that have fused together, whose biosynthetic origin has been speculated to stem from hypotaurine addition to tricyclic pyranoquinones derived from oxa- $6 \pi$-electrocyclization of 
ortho-quinone methide tautomers of bis-benzoquinones [42]. Based on this premise, two biomimetic synthesis of the thiaplidiaquinones scaffold have been reported $[42,43]$. In a first concise total synthesis of thiaplidiaquinone A, the key ring forming steps are both based on biosynthetic considerations and involve the construction of the central benzo[c]chromene quinone unit by an extremely facile oxa- $6 \pi$-electrocyclic ring closure reaction of an ortho-quinone intermediate, derived by tautomerization of a bis-benzoquinone, readily accessed from two simple phenolic precursors. This is followed by the installation of the 1,4-thiazine-dioxide ring by reaction of the benzo[c]chromene quinone with hypotaurine [43]. An alternative biomimetic synthesis of both thiaplidiaquinones A and B has been reported where bis-benzoquinones construction, instead of via a Suzuki-Miyaura reaction [43], was achieved simply by base-mediated dimerization of geranylbenzoquinone. Subsequent reaction with hypotaurine yielded the dioxothiazine regioisomers of thiaplidiaquinones $\mathrm{A}$ and $\mathrm{B}$ [42]. Both conicaquinones A and B showed a marked and selective cytotoxic effects on rat glioma cells [40], and thiaplidiaquinones were strongly cytotoxic against Jurkat cell line, derived from a human T lymphoma, inducing cell death by apoptosis [41]. The pro-apoptotic mechanism of thiaplidiaquinones involves the induction of a strong production of intracellular reactive oxygen species (ROS) in the cells, likely due to the inhibition of the plasma membrane NADH-oxidoreductase (PMOR) system, an important target for anticancer drugs, through interference with the coenzyme-Q binding site [41]. In order to validate the structural assignment made for aplidinones by theoretical means a synthetic approach has been undertaken which yielded some synthetic analogs of aplidinone A in which the geranyl chain is replaced by other alkyl chains [44]; these compounds as well as the natural metabolite $\mathbf{6 3}$ were subjected to cytotoxicity assays and preliminary structure-activity relationships (SAR) studies. Both aplidinone A and its synthetic analogs were shown to possess interesting cytotoxic effects; SAR studies revealed that cytotoxic activity depends on the nature and the length of side chain linked to the benzoquinone ring and, mainly, on its position respect to the dioxothiazine ring. The study also evidenced one of the synthetic analogs as a potent cytotoxic and pro-apoptotic agent against several tumor cell lines, which also inhibits the $\mathrm{TNF} \alpha$-induced NF- $\mathrm{BB}$ activation in a human leukemia T cell line [44].

Figure 8. Prenylated thiazinoquinones from A. conicum.

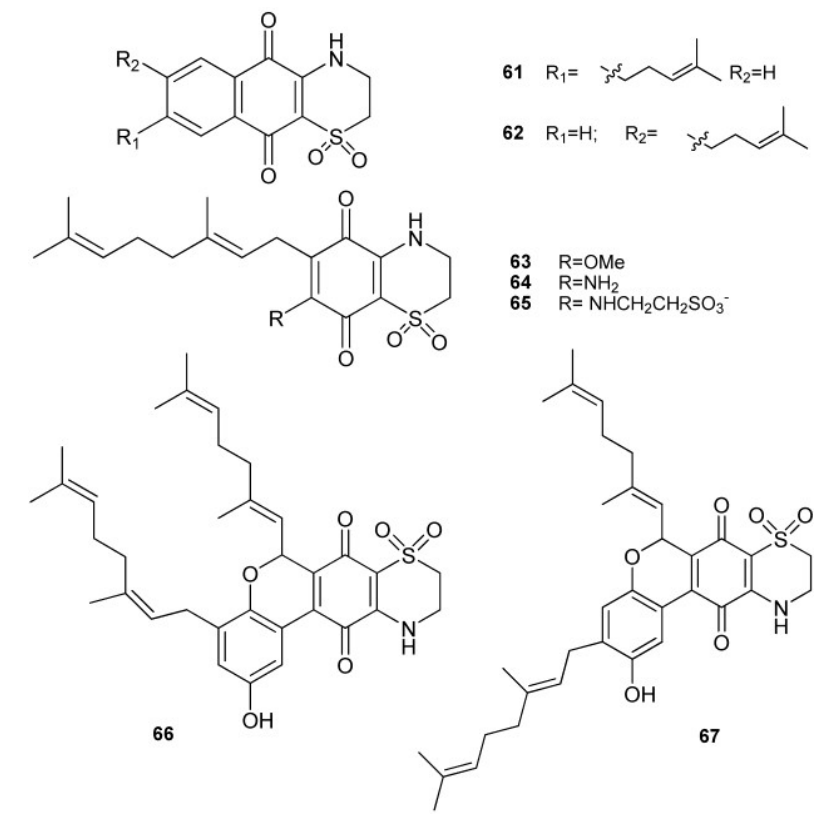




\section{Meroterpenes from Sponges}

Marine sponges have yielded a huge variety of meroterpenes having a terpenoid skeleton varying from sesqui-, di-, sester- or triterpene units.

The large class of sesquiterpene quinones isolated from various species of marine sponges, has attracted the attention of researchers because of their biological properties, including antimicrobial [45], antileukemic [46], anti-malarial [47], immunomodulatory [48,49], and anti-HIV [50] activities. Above all, the cytotoxic and antiproliferative properties of many sesquiterpene quinones/hydroquinones isolated from sponges have supported several studies for the development of new antitumor agents [51,52].

A large family of antineoplastic compounds, named metachromins (68-87), has been isolated from sponges of the genus Spongia, Thorecta and Hippospongia (Figure 9) [53-58]. They exhibited potent antitumor activity against L1210 murine leukemia cells in vitro. Metachromins A-C (68-70) showed also potent coronary vasodilating activity, markedly inhibiting $\mathrm{KCl}(40 \mathrm{mM})$ induced contraction of the rabbit isolated coronary artery with an $\mathrm{IC}_{50}$ value of $3 \times 10^{-6} \mathrm{M}$ each. While metachromins $\mathrm{D}-\mathrm{H}$ (71-75) exhibited cytotoxity against human epidermoid carcinoma $\mathrm{KB}$ cells with $\mathrm{IC}_{50}$ values of $10,0.4,1.9,>10$, and $6.4 \mu \mathrm{g} / \mathrm{mL}$, respectively. Metachromins L (76), M (77), S (83), and T (84) showed cytotoxicity against $\mathrm{L} 1210$ murine leukemia $\left(\mathrm{IC}_{50}, 4.0,3.5,5.2\right.$ and $3.0 \mu \mathrm{g} / \mathrm{mL}$, respectively) and $\mathrm{KB}$ human epidermoid carcinoma cells $\left(\mathrm{IC}_{50}, 4.0,5.4,>10\right.$ and $5.6 \mu \mathrm{g} / \mathrm{mL}$, respectively) in vitro, while metachromins N-R (78-82) did not show such activity $\left(\mathrm{IC}_{50}>10 \mu \mathrm{g} / \mathrm{mL}\right)$. Metachromins $\mathrm{U}-\mathrm{W}(\mathbf{8 5}-\mathbf{8 7})$ were screened against four human tumor cell lines [MCF-7 (breast), SF-268 (CNS), H-460 (lung), and HT-29 (colon)], as well as a mammalian cell line [Chinese hamster ovary (CHO-K1) cells]. All three compounds were found to be cytotoxic against all cell lines, with $\mathbf{8 6}$ being the most active. Surprisingly, 87, possessing a napthoquinone functionality, which is known to impart significant cytotoxic properties to various molecules [58], was significantly less active than both $\mathbf{8 5}$ and $\mathbf{8 6}$. Interestingly, metachromins $\mathrm{N}-\mathrm{R}$ (78-82) [57], which contain both quinone and phenol functions, are inactive, most likely due to the bulky nature of the substituents present on the quinone portion.

In fact, most of sesquiterpene benzo(hydro)quinone isolated from sponges possess a decalin structure, consisting of a drimane or 4,9-friedodrimane skeleton, connected to the quinone/hydroquinone moiety generally via one carbon-carbon bonding. Particularly prolific sources of this sort of meroterpenes are marine sponges belonging to the Dysidea genus.

Compounds having a typical 4,9-friedodrimane skeleton are shown in Figure 10. Avarol (88) and its quinone derivative avarone (89) have been isolated from the marine sponge Dysidea avara [59,60]; the absolute stereochemistry of $\mathbf{8 8}$, which has been stated by spectroscopic and chemical methods in 1976 [61] was later confirmed by crystallographic analysis [62]. Both compounds were discovered as anti-leukemia agents in vitro and in vivo [46,63-66], and later it was found that they had an inhibitory capacity in vitro against HIV-1 [66-68]. Various formulations with high avarol content have been used for the prevention and treatment of psoriasis, dermatitis, skin cancer, tumors in the gastrointestinal tract, urinary tract, and viral infection [69]. Their potent T-lymphotropic cytostatic activity, low toxicity in mice, the ability to cross the blood-brain barrier and the capacity to stimulate the synthesis of interferon make both these compounds optimum candidates for transformations aimed at improving their cytostatic and antiviral activity [63-69]. 
Figure 9. Metachromins.

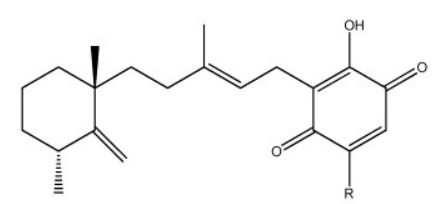

$68 \mathrm{R}=\mathrm{OMe}$

$73 \mathrm{R}=\mathrm{OBu}$
$74 \mathrm{R}=\mathrm{NHCH}_{2} \mathrm{CH}_{2} \mathrm{Ph}$

$75 \mathrm{R}=\mathrm{NHCH}_{2} \mathrm{CH}_{2} \mathrm{CH}\left(\mathrm{CH}_{3}\right)_{2}$

$76 \mathrm{R}=\mathrm{NHCH}_{2} \mathrm{COOH}$

$78 \mathrm{R}=$<smiles>C[C@@H]1C[C@@H]([C@@H](C)O)CN1</smiles>

$80 \mathrm{R}=$<smiles>[2H]c1c(O)c(O)c2c(c1O)O[C@](C)(CC[C@@]1(C)CCC[C@@H](C)C1=C)C=C2</smiles>

$69 \mathrm{R}=\mathrm{H}$<smiles>CC1=CCCC(C)(CCC2(C)C=Cc3c(O)c(N)cc(C)c3C2)C1C</smiles>

72<smiles>C=C1CCCC(C)(C)C1CCC1(C)C=Cc2cc(O)cc(OC)c2O1</smiles>

85<smiles>C=C1CCCC(C)(C)C1CC/C(C)=C/Cc1cc(O)ccc1O</smiles><smiles>C=C1CCCC(C)(C)C1CCc1ccc2c(c1)C(=O)C=C(OC)C2=O</smiles>

Figure 10. 4,9-Friedodrimane-type skeleton containing meroterpenes of the avarol/avarone series.
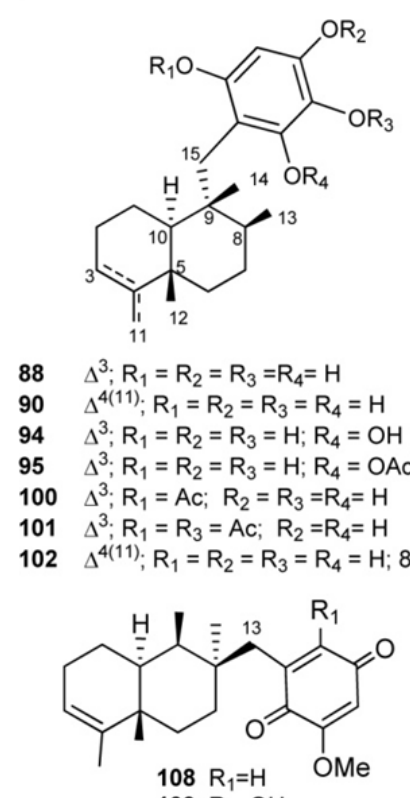

$109 \mathrm{R}_{1}=\mathrm{OH}$

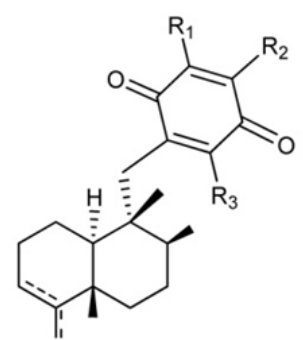

$89 \Delta^{3} ; \mathrm{R}_{1}=\mathrm{R}_{2}=\mathrm{R}_{3}=\mathrm{H}$

$91 \Delta^{4(11)} ; R_{1}=R_{2}=R_{3}=H$

$92 \Delta^{3} ; \mathrm{R}_{1}=\mathrm{R}_{3}=\mathrm{H} ; \mathrm{R}_{2}=\mathrm{OMe}$

$93 \Delta^{4(11)} ; \mathrm{R}_{1}=\mathrm{R}_{3}=\mathrm{H} ; \mathrm{R}_{2}=\mathrm{OMe}$

$96 \Delta^{3} ; \mathrm{R}_{1}=\mathrm{OH} ; \mathrm{R}_{2}=\mathrm{R}_{3}=\mathrm{H}$

$97 \quad \Delta^{3} ; \mathrm{R}_{1}=\mathrm{R}_{2}=\mathrm{H} ; \mathrm{R}_{3}=\mathrm{OAC}$

$98 \Delta^{3} ; \mathrm{R}_{1}=\mathrm{R}_{3}=\mathrm{OH} ; \mathrm{R}_{2}=\mathrm{H}$

$99 \Delta^{3} ; \mathrm{R}_{1}=\mathrm{H} ; \mathrm{R}_{2}=\mathrm{OMe} ; \mathrm{R}_{3}=\mathrm{OH}$

$103 \Delta^{4(11)} ; \mathrm{R}_{1}=\mathrm{R}_{2}=\mathrm{R}_{3}=\mathrm{H} ; 8,9,10-e p i$

$104 \Delta^{4(11)} ; \mathrm{R}_{1}=\mathrm{OMe} ; \mathrm{R}_{2}=\mathrm{H} ; \mathrm{R}_{3}=\mathrm{OH}$

$105 \Delta^{4(11)} ; \mathrm{R}_{1}=\mathrm{OMe} ; \mathrm{R}_{2}=\mathrm{H} ; \mathrm{R}_{3}=\mathrm{OH} ; 5$-ерi

$106 \Delta^{3} ; \mathrm{R}_{1}=\mathrm{OMe} ; \mathrm{R}_{2}=\mathrm{H} ; \mathrm{R}_{3}=\mathrm{OH}$

$107 \Delta^{3} ; \mathrm{R}_{1}=\mathrm{OMe} ; \mathrm{R}_{2}=\mathrm{H} ; \mathrm{R}_{3}=\mathrm{OH} ; 5-e p i$

A number of derivatives of avarol and avarone have been isolated from other Dysidea species. Examples are neoavarol (90), neoavarone (91), 4'-methoxyavarone (92) and 4'-methoxyneoavarone (93), isolated from a sample of Dysidea sp. collected in Okinawa [70], and 6'-hydroxyavarol (94), 6'-acetoxyavarol (95), 3'-hydroxyavarone (96), 6'-acetoxyavarone (97), 3',6'-dihydroxyavarone (98) and 6'-hydroxy-4'-methoxyavarone (99), isolated from Dysidea cinera [71]. Some of these compounds 
showed cytotoxic activity, 3'-hydroxyavarone (96), 6'-acetoxyavarol (95) and 3,6'-dihydroxyavarone (98) exhibiting high potency against P-388 mouse lymphoma. From different extracts of Dysidea avara collected from different places (Japan, the Solomon Islands, and others), mono-(100), diacetyl-(101), and 6'-hydroxy-5'-acetylavarol have been isolated $[49,72,73]$. A number of avarol derivatives exhibited interesting activity in enzyme assays measuring inhibition of various functions of HIV-1 reverse transcriptase [74].

From the Pacific sponge Dysidea arenaria, a pair of mildly cytotoxic compounds, arenarol (102) and arenarone (103), have been isolated having the same rearranged sesquiterpene skeleton as avarol, but with cis- rather than trans-decalin stereochemistry [75].

Ilimaquinone (104), first isolated from the Hawaiian sponge Hippospongia metachromia [76] and successively recovered in several other sponge species along with its 5-epi-analogous (105) and both isospongiaquinone (106) and 5-epi-isospongiaquinone (107) [77-80]. In 1987 Capon reversed the absolute stereochemistry of (-)ilimaquinone, placing (+)arenarol and (-)ilimaquinone in the same $8 S, 9 R$ absolute stereochemical series [81]. Several important activities have been reported for ilimaquinone, including anti-HIV activity [50] and ability to protect cells from the toxic effects of ricin and diphtheria toxin [82]. Particularly, it has been suggested that 104 induces a concentration-dependent antiproliferative effect in several types of cancer cell lines. The anticancer mechanism of ilimaquinone in the representative PC-3 cells was identified; it induces a time-dependent increase in G1 phase arrest and a subsequent increase in the hypodiploid sub-G1 phase (apoptosis) of the cell cycle. Although ilimaquinone-induced Golgi vesiculation $[83,84]$, the data showed that the inhibition of cancer cell growth did not occur through Golgi fragmentation. Ilimaquinone (104) also inhibited the DNA binding of NF- $\kappa \mathrm{B}$; however, this inhibitory effect cannot explain the ilimaquinone-induced anticancer effect. In brief, it is suggested that ilimaquinone (104) induces its antiproliferative effect through the G1 arrest of the cell cycle and the up-regulation and nuclear translocation of CHOP/GADD153 [85]. 5-epi-Ilimaquinone (105) showed cytotoxic activity against P-388 leukemia cells $(2.2 \mu \mathrm{g} / \mathrm{mL})$ and different solid tumors: A-549 $(0.9 \mu \mathrm{g} / \mathrm{mL})$, HT-29 $(3.4 \mu \mathrm{g} / \mathrm{mL})$ and B16/F10 $(1.1 \mu \mathrm{g} / \mathrm{mL})$ [80].

Bolinaquinone (108) is a cytotoxic sesquiterpene isolated from a Dysidea sponge in which quinone moiety is located on an unusual carbon of the 4,9-friedodrimane skeleton [86]. This compound was cytotoxic against HCT-116 human colon carcinoma $\left(\mathrm{IC}_{50}=1.9 \mu \mathrm{g} / \mathrm{mL}\right)$ and it has been demonstrated to act by interfering with or damaging DNA. 21-dehydroxybolinaquinone (109), isolated from the Hainan sponge Dysidea villosa, showed moderate PTP1B inhibitory activity and cytotoxicity, with IC50 values of 39.5 and $19.5 \mathrm{mM}$, respectively [87].

Examples of meroterpenes of the drimane series (Figure 11) are dactylospongiaquinone (110) and spongiaquinone (111), isolated from the sponge Dactylospongia n. sp. [79,88], isohyatellaquinone (112), dictyoceratidaquinone (113), mamanuthaquinone (114), and hyatellaquinone (115) from both Dactylospongia and Fasciospongia sponges [89-92]. Total synthesis of both hyathellaquinone (115) and spongiaquinone (111) has been reported [93,94]; particularly, synthesis of (-)-hyatellaquinone led to revision of absolute configuration of the naturally occurring $(+)$-isomer [93]. The anti-inflammatory sesquiterpene-quinone $\mathbf{1 1 6}$ has been isolated from the New Zealand sponge Dysidea cf. cristagalli [95].

Wiedendiols A (117) and B (118) were isolated from the marine sponge Xestospongia wiedenmayeri, collected in the Bahamas [96]. The CETP-SPA inhibition assays carried out with these compounds revealed an $\mathrm{IC}_{50}=5 \mu \mathrm{M}$ in both cases. Later, the inhibition of CETP was verified using a precipitation 
method to separate lipoproteins after incubation of HDL radiolabeled with LDL and CETP. In this assay, both 117 and 118 had an $\mathrm{IC}_{50}$ of 1.0 and $0.6 \mu \mathrm{M}$, respectively. Wiedendiol $\mathrm{B}$ is a ten-fold stronger inhibitor of cyclooxigenase-2 than the reference compound indomethacine [97].

Smenodiol (119), isolated from a Seychellean sponge belonging to the genus Smenospongia [98], and compounds 120 and 121, isolated from Dactylospongia elegans [80], feature a carboxilate function on the aromatic ring; smenodiol could be considered a possible direct precursor of pelorol (122), isolated from D. elegans [99], as it is a simple cyclization product thereof (Figure 11).

Figure 11. Drimane-type skeleton containing meroterpenes.
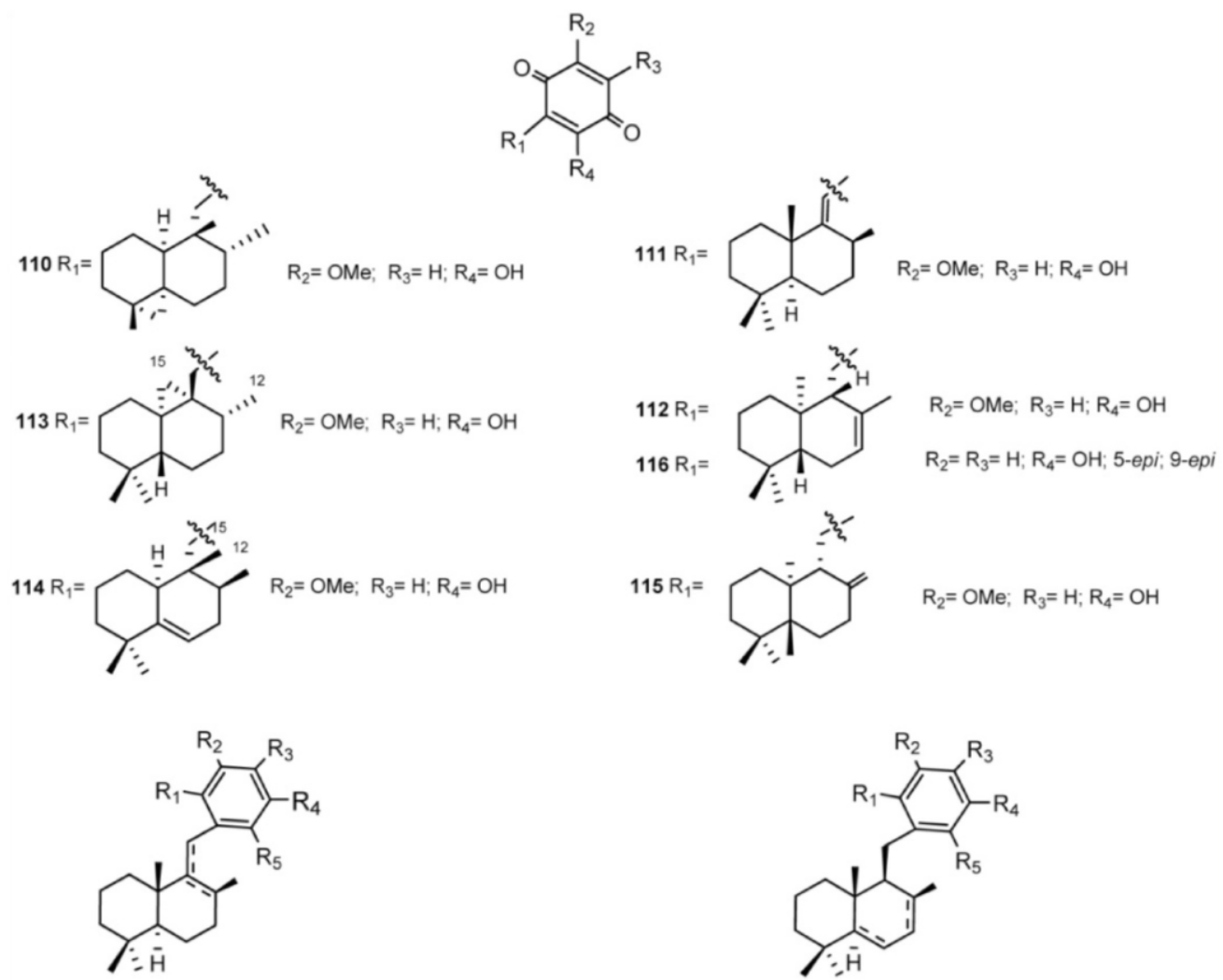

$117 \Delta^{8}: R_{1}=R_{2}=\mathrm{OH}: \mathrm{R}_{3}=\mathrm{R}_{4}=\mathrm{H}: \mathrm{R}_{5}=\mathrm{OCH}_{3}$

$118 \Delta^{9}(14) ; R_{1}=R_{2}=\mathrm{OH} ; \mathrm{R}_{3}=\mathrm{R}_{4}=\mathrm{H} ; \mathrm{R}_{5}=\mathrm{OCH}_{3}$

$124 \Delta^{9}(14) ; R_{1}=R_{3}=R_{4}=\mathrm{OH} ; R_{2}=C H O ; R_{5}=H$

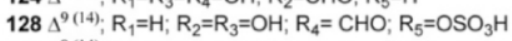

$129 \Delta^{9}$ (14): $\mathrm{R}_{1}=\mathrm{H}: \mathrm{R}_{2}=\mathrm{R}_{5}=\mathrm{OSO}_{3} \mathrm{H} ; \mathrm{R}_{3}=\mathrm{OH} ; \mathrm{R}_{4}=\mathrm{CHO}$

$131 \Delta^{8} ; \mathrm{R}_{1}=\mathrm{OSO}_{3} \mathrm{Na} ; \mathrm{R}_{2}=\mathrm{OH} ; \mathrm{R}_{3}=\mathrm{R}_{5}=\mathrm{H} ; \mathrm{R}_{4}=\mathrm{CH}_{2} \mathrm{OH}$<smiles>[R]Cc1c([R])c([R])c([R])c([R])c1[R]</smiles>

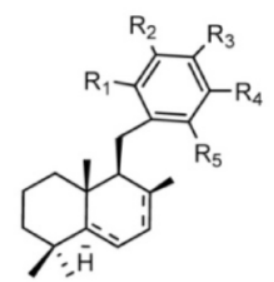

$119 \Delta^{7} ; \mathrm{R}_{1}=\mathrm{OH} ; \mathrm{R}_{2}=\mathrm{R}_{3}=\mathrm{R}_{5}=\mathrm{H} ; \mathrm{R}_{4}=\mathrm{COOMe}$ $120 \Delta^{7} ; R_{1}=O H ; R_{2}=R_{3}=R_{5}=H ; R_{4}=C O O M e$ $121 \Delta^{7} ; \mathrm{R}_{1}=\mathrm{R}_{2}=\mathrm{R}_{3}=\mathrm{OH} ; \mathrm{R}_{4}=\mathrm{COOMe} ; \mathrm{R}_{5}=\mathrm{H}$ $125 \Delta^{7} ; \mathrm{R}_{1}=\mathrm{OSO}_{3} \mathrm{Na} ; \mathrm{R}_{2}=\mathrm{CHO} ; \mathrm{R}_{3}=\mathrm{R}_{4}=\mathrm{OH} ; \mathrm{R}_{5}=\mathrm{H}$<smiles>COC(=O)c1cc(O)c(O)c2c1C1(C)CCC3(C)[C@H](C)CCC[C@]3(C)C[C@H]21</smiles><smiles>C[Y9](=O)[O-]</smiles>

$\mathrm{R}_{2}=\mathrm{CHO} ; \mathrm{R}_{3}=\mathrm{R}_{6}=\mathrm{OH} ; \mathrm{R}_{4}=\mathrm{R}_{5}=\mathrm{H}$<smiles>[R6]c1cc([R6])c(CC2[C@@H]3CCCC(=C)[C@@]3(C)CC[C@H]2C)c(C)c1[R]</smiles>

$\mathrm{R}_{2}=\mathrm{OSO}_{3} \mathrm{Na} ; \mathrm{R}_{3}=\mathrm{CHO} ; \mathrm{R}_{4}=\mathrm{R}_{5}=\mathrm{OH} ; \mathrm{R}_{6}=\mathrm{H}$

$127 \Delta^{4}(11) ; \mathrm{R}_{1}=\mathrm{OSO}_{3} \mathrm{Na} ; \mathrm{R}_{2}=\mathrm{OH} ; \mathrm{R}_{3}=\mathrm{CHO}$ $130 \Delta^{4}(11) ; \mathrm{R}_{1}=\mathrm{OSO}_{3} \mathrm{Na} ; \mathrm{R}_{2}=\mathrm{OH} ; \mathrm{R}_{3}=\mathrm{CH}_{2} \mathrm{OH}$ $132 \Delta^{4(11)} ; \mathrm{R}_{1}=\mathrm{R}_{2}=\mathrm{OH} ; \mathrm{R}_{3}=\mathrm{COOH}$ 
An aldehyde function is the distinctive feature of siphonodictyals A-D (123-126), G (127), B2 (128), and B3 (129), which have been isolated from Siphonodictyon species along with the relevant alcohols siphonodictyols $G$ (130) and H (131) and siphonodictyoic acid (132); most of them were sulfated [100-102]. The isolated compounds were tested for antimicrobial activity (antibacterial, antifungal); it has been suggested that the different substituents on the aromatic moieties have an impact on activity and that the ortho-hydroquinone structure may be the active center of the molecules. It is likely that the hydroquinone is oxidized in the metabolism of the assay organisms to yield the more toxic ortho-quinone.

The presence of aminoquinone compounds is not very common in natural products; however, several sesquiterpenes quinones/hydroquinones, with such a drimane or a 4,9-friedodrimane, where the aromatic fragment is substituted with simple amines and amino acids have been isolated from sponges (Figures 12 and 13). The sesquiterpene aminoquinones smenospongine (133), smenospongiarine (134), smenospongidine (135), and their corresponding 5-epimers 136-138, have been isolated from different sponge species $[47,70,103,104]$. Erythroid differentiation of K562 cells induced by compounds 133-138 and other related compounds has been studied. On the basis of structure-activity relationship studies, the following evidences were obtained: (a) the quinone structure is indispensable; (b) the amino group should play an important role; (c) the substituents at the amino group are not crucial; (d) the configuration at the C-5 in sesquiterpene part is not important $[105,106]$. Smenospongines B (139) and C (140) were isolated from D. elegans collected in Australia along with the sesquiterpene benzoxazole nakijinol B (141) and its diacetyl derivative 142 [107]. The biological activities of these compounds were established against a panel of human tumor cell lines, as well as a normal mammalian cell line. The compounds were found to have cytotoxic activities in the range 1.8-46 $\mu \mathrm{M}$ and appeared to lack selectivity for tumor versus normal cell lines. The presence of two bulky acetate moieties resulted in an approximate two-fold increase in the activity of $\mathbf{1 4 2}$ compared to the diol 141. One possible explanation for this increase in activity is that the acetate groups may contribute to greater bioavailability through enhanced membrane permeation after which metabolism, possibly hydrolysis by esterases, releases the active compounds intracellularly [108]. For 139 and 140, the additional methylene in the nitrogen-substituted side chain had the effect of reducing observed activity by a factor of 2 (Figure 12).

From different extracts of Dysidea avara collected from different places (Japan, the Solomon Islands, and others), melemeleone A (143), melemeleone B (144) have been isolated possessing a taurine moiety linked to the quinone ring. Melemeleone B (144) was proved to have a certain activity against PTK (Protein Tyrosine Kinase) pp60 ${ }^{\mathrm{v}-\mathrm{sarc}}$ (dose: $20 \mu \mathrm{g} / \mathrm{mL}$ ) with an $\mathrm{IC}_{50}=28 \mu \mathrm{M}$ [49]. Dysidine (145), found in the Hainan sponge Dysidea villosa, also features a taurine residue on the aromatic portion, which is otherwise connected at C-11 of the decalin ring [109]. Compound 145 effectively activated the insulin signaling pathway, greatly promoted glucose uptake in 3T3-L1 cells, and showed strong insulin-sensitizing activities. The potential targets of action for dysidine were probed, and the results indicated that dysidine exhibited its cellular effects through activation of the insulin pathway, possibly through the inhibition of protein tyrosine phosphatases, with more specific inhibition against protein tyrosine phosphatase 1B (PTP1B) [110]. 3'-Aminoavarone (146), and 3'-phenethylaminoavarone (147), have been isolated from the marine sponge Dysidea sp. collected in Papua New Guinea along with avinosol (148), which is the first example of a naturally occurring meroterpenoid-nucleoside conjugate. Avinosol showed antiinvasion activity in a cell-based assay [111]. The structures of popolohuanones 
A-F (148-154), isolated from different species of the genus Dysidea [66,112-114], are formed by two subunits. Popolohuanone A (149) and popolohuanone F (154) showed DPPH radical scavenging activity, with an $\mathrm{IC}_{50}$ value of $35 \mu \mathrm{M}$ [114]. Popolohuanone E (153) was revealed as a potent topoisomerase II inhibitor with selective cytotoxicity against the A549 non-small cell human lung cancer cell line [113] (Figure 12).

Figure 12. Amino- and amino acid- substituted quinone containing meroterpenes.

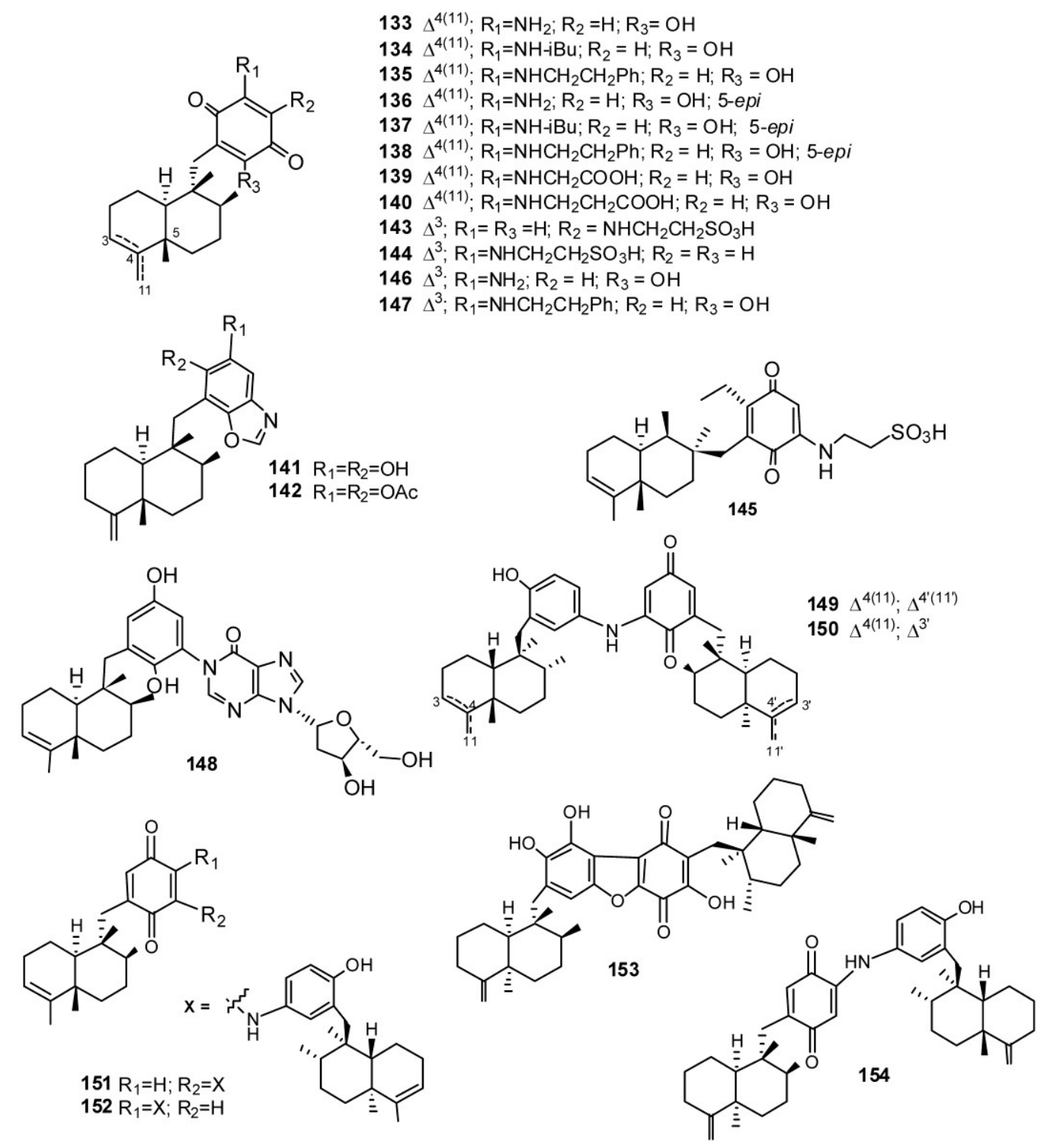

Nakijiquinones A-R (155-172) and nakijinol (173) (Figure 13) constitute a large class of sesquiterpenequinones of natural origin with an amino acid (nakijiquinones $\mathrm{A}-\mathrm{D}, \mathbf{1 5 5}-\mathbf{1 5 8}$ ) an heterocyclic moiety (nakijinol, 173), or an amino acid-derived amino group (nakijiquinones G-R, 161-172) which have been isolated from five collections of Okinawan marine sponge of the Family Spongiidae [115-119]. Nakijiquinones E (159) and F (160) were the first dimeric sesquiterpeneoids possessing a 3-aminobenzoate moiety [117]. Nakijiquinones A-D (155-158) showed in vitro cytotoxicity against $\mathrm{L}-1210$ ( $\mathrm{IC}_{50}$ values between 2.8 and $8.1 \mu \mathrm{g} / \mathrm{mL}$ ) and $\mathrm{KB}$ ( $\mathrm{IC}_{50}$ values between 1.2 and $7.6 \mu \mathrm{g} / \mathrm{mL}$ [115], while nakijiquinones G-I (143-145), slightly cytotoxic, and C (141) showed inhibitory activity against 
protein tyrosine kinase HER2 [116,118]. Studies on the total synthesis and structure-activity relationship of nakijiquinones have been performed by Waldmann et al. and it was found that simplified analogs of nakijiquinones A-D exhibited inhibitory activities against different kinds of tyrosine kinases [120]. Nakijiquinones $\mathrm{J}-\mathrm{R}$ at $1 \mathrm{mM}$ were tested for inhibitory activities against EGFR and HER2 tyrosine kinases. Among them, nakijiquinones $\mathrm{P}$ and $\mathrm{R}$ exhibited inhibitory activities against EGFR (76 and $>99 \%$ inhibition, respectively), while nakijiquinones $\mathrm{N}, \mathrm{O}$ and $\mathrm{R}$ showed inhibitory activities against HER2 (66\%, 59\% and 52\% inhibition, respectively). The HER2/Neu tyrosine kinase receptor is hugely overexpressed in about $30 \%$ of primary breast, ovary, and gastric carcinomas. Nakijiquinones are the only naturally occurring inhibitors of this important oncogene $[51,120]$.

Figure 13. Nakijiquinones and nakijinol.

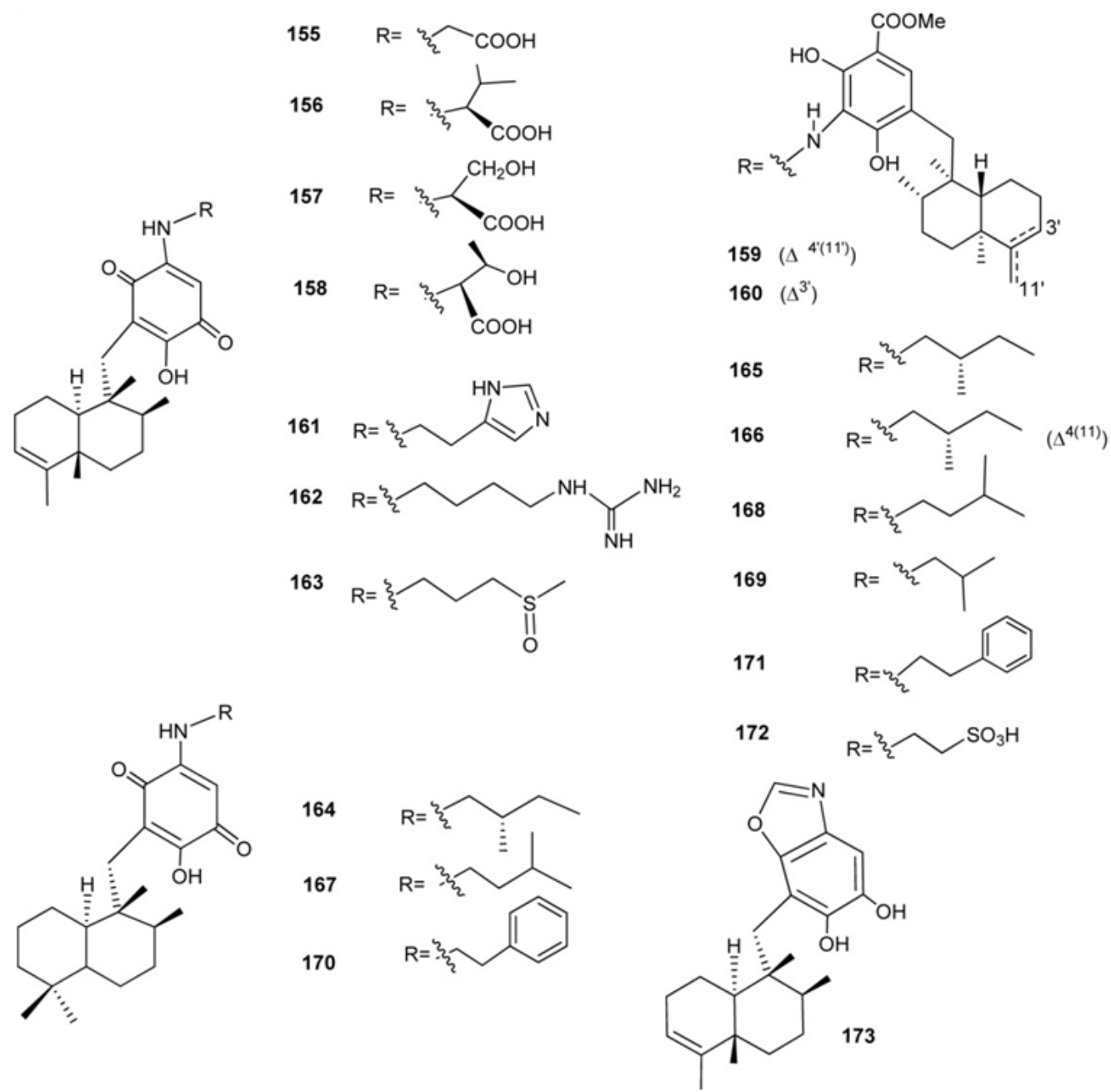

There are some compounds that also have a fourth ring, through an oxygen (most times) or carbon bridge between the decalin and the benzo(hydro)quinone ring (Figure 14). Dactyloquinones A and B (174 and 175), having a six-membered-ring made by ether linkages between C-10 and C-17 of ilimaquinone and 5-epi-ilimaquinone, respectively [121], dactyloquinones D and E (176 and 177), both possessing a six membered-ring made from ether linkages between $\mathrm{C}-8$ and $\mathrm{C}-17$ of of ilimaquinone and 5-epi-ilimaquinone, respectively [122], have been isolated from a collection of Dactylospongia elegans at Okinawa (Japan). An oxygen bridge between the benzo(hydro)quinone moiety linked at C-11 and C-8 
or C-10 to form dihydropyran rings has been also observed in aureol (178) [123], strongylin (179) [124], smenoqualone (180) [45], cyclospongiaquinone-1 (181) [79,88], dehydrocyclospongiaquinone-1 (182) [79,88], and ent-chromazonarol (183), isolated from Dysidea pallescens [125], whose structure was confirmed by chemical synthesis performed from (-)-scalareol [126]. The epimer of 183, 8-epichromazonarol (184), was isolated from Smenospongia aurea [123]. Interestingly, ent-chromazonarol (183) resulted moderately cytotoxic activity against P-388, A-549. HT-29 and MEL-28 cells, while its enantiomer chromazonarol, isolated from a brown alga, was inactive [127]. An enantioselective cyclization of 2-(polyprenyl)phenol derivatives to afford polycyclic terpenoids bearing a chroman skeleton such as (-)-chromazonarol by a new artificial cyclase has been described [128]. Puupehenone (185) possessing a drimane skeleton differs from typical natural sesquiterpene quinones by having a quinone-methide system. First isolated by Scheuer and co-workers from the sponge tentatively identified as Chondrosia chucalla [129], $\mathbf{1 8 5}$ has so far been isolated from different sponges, mainly of orders Verongida and Dictyoceratida, together with many other puupehenone-derived congeners (186-192) engendered by the presence of the highly electrophilic quinone-methide system and oxygen functionalities [129-137] (Figure 11). The puupehenones display a wide range of biological properties as angiogenesis inhibitors [138], antitumor [130,131], antifungal [48,129], antiviral [48], antimalarial [130], antituberculosis [139], immunomodulatory [138,140], and antioxidant agents [141]. The total synthesis of $(+)$-puupehenone (185) was achieved in ten steps starting from commercially available $(+)$-sclareolide [142].

Structures with a fourth five-membered oxygen spiranic ring are cyclospongiaquinone-2 (193) $[79,88]$, its analogs 7,8-dehydrocyclospongiaquinone-2 (194) and 9-epi-7,8-dehydrocyclospongiaquinone-2 (195) [89], and the corallidyctals A-D (196-199), isolated from the marine sponge Aka (=Siphonodictyon) coralliphagum [102,143]. Both corallidictyal A (196) and B (197) inhibit PKC with an $\mathrm{IC}_{50}=28 \mu \mathrm{M}$, while assays addressing another cAMP-dependent kinase did not afford inhibition at concentrations of $300 \mu \mathrm{M}$, indicating its selectivity. Further, the assays revealed selectivity against the $\alpha$ isoform of PKC [102]. Corallidictyals C (198) and D (199) were tested in antiproliferative assays using cultures of mouse fibroblasts and activity was linked to the presence of the ortho-hydroquinone moiety [143]. Uncommon cyclizations are observed in the aminoquinone cyclosmenospongine (200) [144,145], neodactyloquinone (201) [146], and dactyloquinone C (202) [122]; this latter compounds, together with bis(sulfato)-cyclosiphonodictyol A (203), isolated from Siphonodictyon coralliphagum, represent the only examples with a further seven-membered ring. Compound $\mathbf{2 0 3}$ showed inhibitory activity against the binding of $\left[{ }^{3} \mathrm{H}\right]-\mathrm{LTB}_{4}$ to human neutrophils, with $\mathrm{IC}_{50}=44.5 \mu \mathrm{M}$ [147] (Figure 14).

Sesquiterpene benzo(hydro)quinones with more unusual and/or complex structures are showed in Figure 15. Frondosins A-E (204-208), from Dysidea frondosa, were found to be inhibitors of interleukin- 8 receptors and protein kinase $\mathrm{C}$ in the low micromolar range [148]. 
Figure 14. Meroterpenoids with a fourth ring originated by an ether linkage between the benzo(hydro)quinone and terpene moieties.
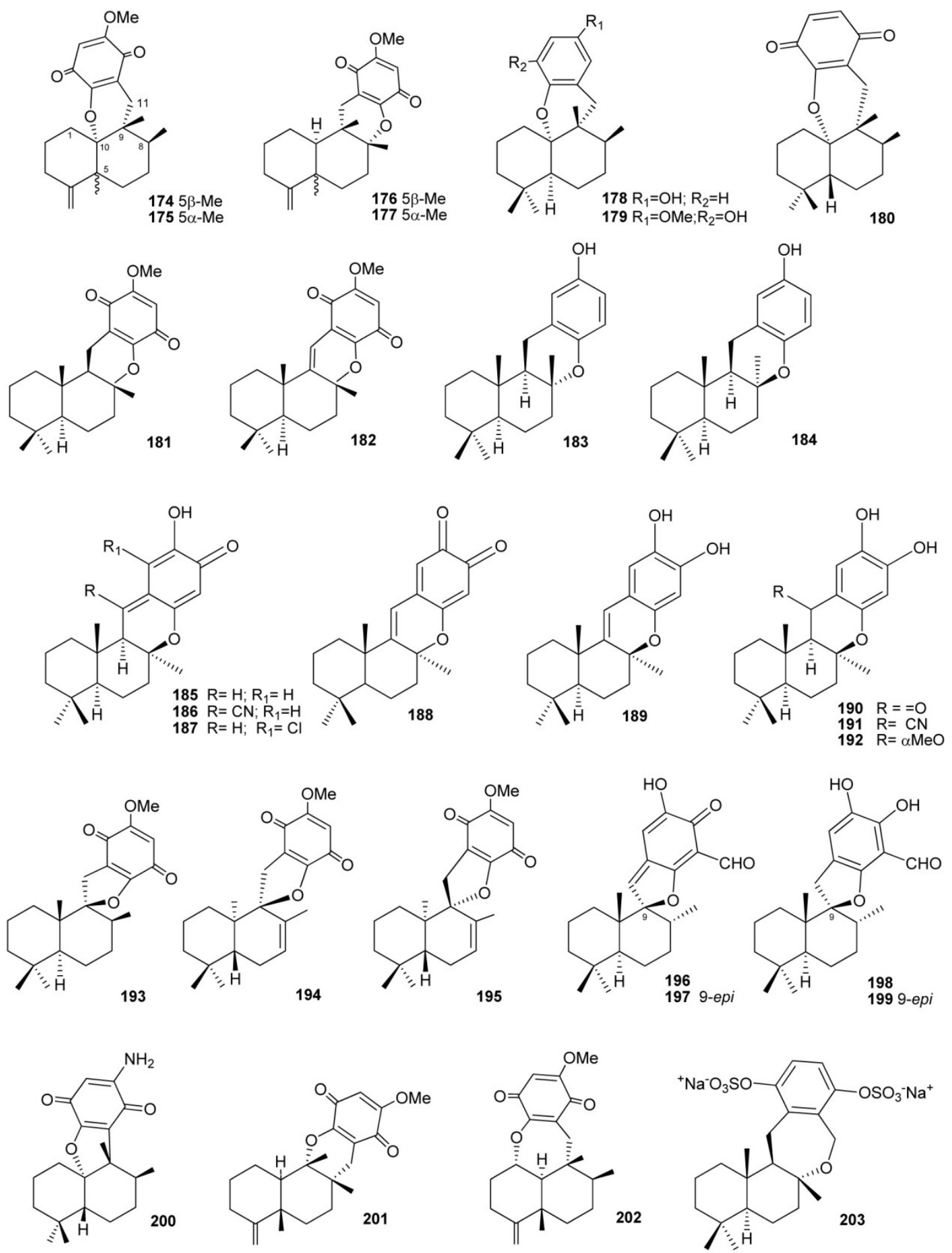

Dysidavarones A-D (209-212), isolated from Dysidea avara, possess the unprecedented "dysidavarane" carbon skeleton. Their cytotoxic activity against four human cancer cell lines, cervix (HeLa), lung (A549), breast (MDA231), and hepatoma (QGY7703), were evaluated. In particular, Dysidavarones A (209) showed a growth inhibitory effect against HeLa cells with an $\mathrm{IC}_{50}$ value of $39.9 \mu \mathrm{M}$, and dysidavarone $\mathrm{D}(\mathbf{2 1 2})$ showed inhibitory effects against the four cell lines with $\mathrm{IC}_{50}$ values of 28.8, 21.4, 11.6, and 28.1 $\mu \mathrm{M}$, respectively. In addition, dysidavarones A (209) and D (212) also 
showed inhibitory activity on protein tyrosine phosphatase PTP1B with $\mathrm{IC}_{50}$ values of 9.98 and $21.6 \mu \mathrm{M}$, respectively [149].

Figure 15. Sesquimeroterpenoids with unusual and/or complex structures.<smiles>CC1CCCC2=C1CC[C@H](C)[C@H](C)[C@H]2c1cccc(O)c1</smiles><smiles>CC1CCCC2=C1CC[C@H](C)c1oc3ccc(O)cc3c12</smiles><smiles>C[C@H]1CCC2=C(CCCC2(C)C)O[C@H]1C</smiles><smiles>C[C@H](O)[C@H]1CCC2=C(CCCC2(C)C)[C@@H]1C(O)O</smiles>

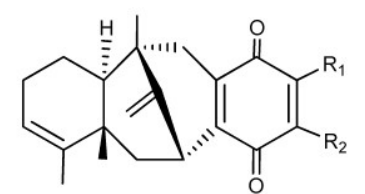
$209 \mathrm{R}_{1}=\mathrm{OEt} ; \mathrm{R}_{2}=\mathrm{H}$ $210 R_{1}=H ; R_{2}=O E t$

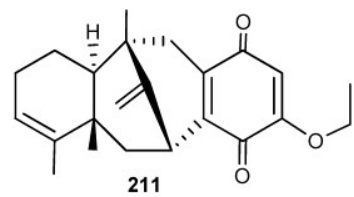<smiles>CCOC1=CC(=O)C2=C(C[C@H]3C[C@H]2[C@H]2CCC=C(C)[C@@]32C)C1=O</smiles><smiles>CC12CCC(=O)c3coc(c31)C(=O)c1cc3c(cc12)C(=O)C=CC3=O</smiles><smiles>CC12CCCc3coc(c31)C(=O)c1cc3c(cc12)C(=O)C=CC3=O</smiles><smiles></smiles>

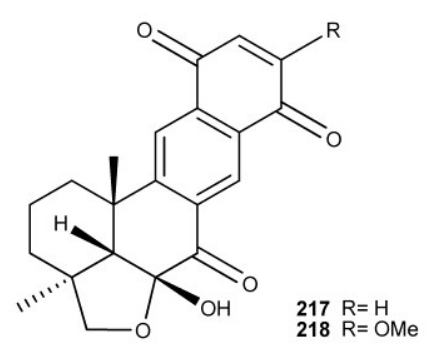<smiles>CC12CCC[C@@]3(C)COC(O)(C(=O)c4cc5c(cc41)C(=O)C1=C(NCCO1)C5=O)C23C</smiles><smiles>CC12CCC[C@@]3(C)COC(O)(C(=O)c4cc5c(O)ccc(O)c5cc41)[C@]23C</smiles>

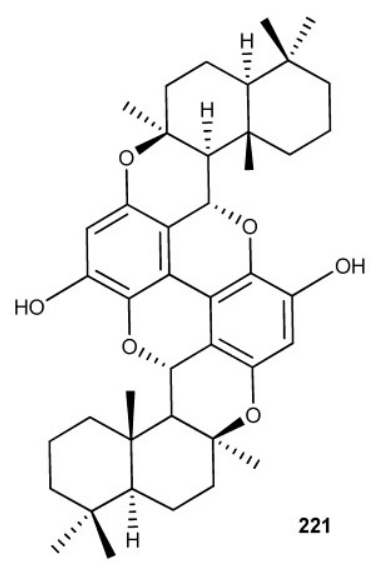

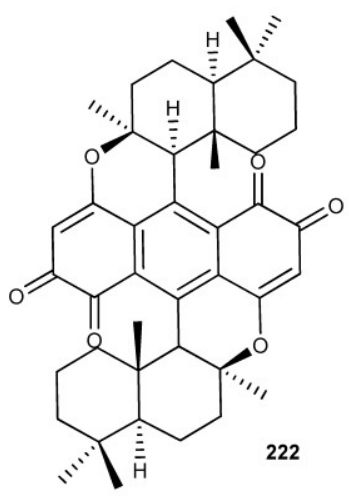

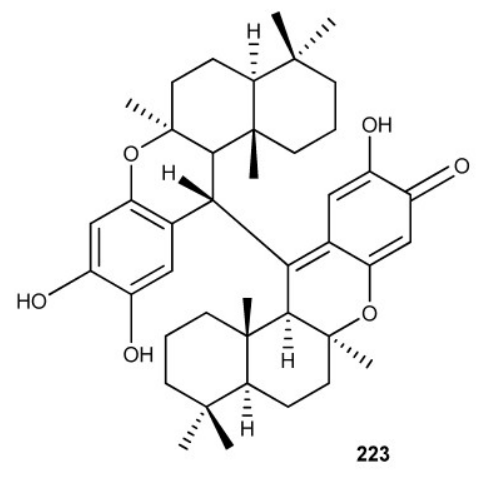

Investigation of Pacific sponges of the genus Xestospongia, yielded some quinone compounds with biological activites, halenaquinone (213) and xestoquinone (214) [150,151]. Both compounds showed cardiotonic properties and inhibitory activity against $\mathrm{Ca}^{2+}$ ATPase, phosphatidylinositol 3-kinase, 
protein-tyrosine kinase, and mammalian topoisomerase I. In addition, halenaquinone (213) showed cytotoxic activity against $\mathrm{KB}$ and $\mathrm{P} 388$ cell lines and it inhibited recombinant human $\mathrm{Cdc} 25 \mathrm{~B}$ in vitro with $\mathrm{IC}_{50}$ values of $0.7 \mu \mathrm{M}[152,153]$. From an Adocia sp. sponge from Truk Lagoon were isolated adociaquinones A (215) and B (216) [154]. They exihibited a cytotoxic activity toward P388, HCT, KB16, and HEP-3B cell lines. Moreover, compound 216 inhibited recombinant human Cdc25B in vitro with $\mathrm{IC}_{50}$ values of $0.07 \mu \mathrm{M}$ [152].

Alisiaquinones A-C (217-219) and alisaquinol (220) [155], isolated from a New Caledonian deep water sponge, are related to xestoquinone, halenaquinone, adociaquinones, but they show an unusual substitution pattern on the furan ring. These new meroterpenes displayed mild activity with micromolar range on two enzymatic targets of importance for the control of malaria, the plasmodial kinase Pfnek-1 and a protein farnesyl transferase (PFT) as well as on different chloroquine-sensitive and chloroquine-resistant strains of Plasmodium falciparum [155].

Particularly, alisiaquinone C (215), bearing the taurine substituent, displayed a submicromolar activity on $P$. falciparum and a competitive selectivity index on the different plasmodial strains, especially on the chloroquine-resistant strain PfFcMC29. For alisiaquinones A (217) and C (219), the in vivo activity was also investigated, but they displayed a relatively high level of toxicity. Bispuupehenone (221), dipuupehedione (222), and diplopuupehenone (223) are dimeric molecules isolated from Dysidea sp. and Hyrtios sp. [131,137,141]. The unsymmetrical structure of diplopuupehenone comprises puupehenone and puupehenol segments. Bioactivity assays of these compounds unveiled the cytotoxic activity of dipuupehedione (222) against $\mathrm{KB}$ cells $\left(\mathrm{ED}_{50}=3 \mu \mathrm{g} / \mathrm{mL}\right)$ [131] and the antioxidant properties of diplopuupehenone (223). Compound 223 exhibited the greatest potency in scavenging the 2,2-diphenyl-1-picrylhydrazyl (DPPH) free radical with an $\mathrm{IC}_{50}$ value of $8 \mu \mathrm{M}$, in comparison with that of puupehenone (185, $\left.\mathrm{IC}_{50} 32 \mu \mathrm{M}\right)$, bispuupehenone (221), $\mathrm{IC}_{50} 120 \mu \mathrm{M}$ ) and the standard antioxidant Trolox $\left(\mathrm{IC}_{50} 16 \mu \mathrm{M}\right)$ [131].

The meroterpene sulfate fascioquinol E (224), isolated from a Fasciospongia sp., (Figure 16) is a rare example of diterpene benzo(hydro)quinone with a linear terpene moiety [156]. Fascioquinol $\mathrm{E}$ is an inhibitor of protein tyrosine phosphatase $\mathrm{CpsB}$, which unexpectedly inhibited the growth of Gram-positive pathogens. CpsB is a member of the polymerase and histidinol phosphate phosphatase (PHP) domain family. Another member of this family found in a variety of Gram-positive pathogens is DNA polymerase PolC and this competes away fascioquinol $\mathrm{E}$ inhibition of CpsB phosphatase activity. It was showed that fascioquinol E not only inhibits the phosphatase activity of $\mathrm{CpsB}$, but also ability of PolCPHP to catalyse the hydrolysis of pNP-TMP. This suggests that PolC may be the essential target of fascioquinol E, and that the PHP domain may represent an as yet untapped target for the development of novel antibiotics $[157,158]$.

Cacospongins B-D (225-227), from Cacospongia sp. and jaspaquinol (228) from the sponges Jaspis splendens and Suberea sp. [159,160] exhibit a monocyclic terpene portion. Compounds 227 and 228 showed significant antimicrobial activity against $S$. epidermidis ( $\mathrm{MIC}=20$ and $5.0 \mu \mathrm{g} / \mathrm{mL}$, respectively) though weaker in comparison with vancomycin [161,162] (MIC $=0.625 \mu \mathrm{g} / \mathrm{mL}$ ). Compound 228 showed also to be active as human 15-lipoxygenase and 12-lipoxygenase inhibitor with $\mathrm{IC}_{50}=0.3 \pm 0.1 \mu \mathrm{M}$ and $\mathrm{IC}_{50}=4.5 \pm 1.0 \mu \mathrm{M}$, respectively [163]. 
Figure 16. Diterpene benzo(hydro)quinones with linear or monocyclic terpene moieties.

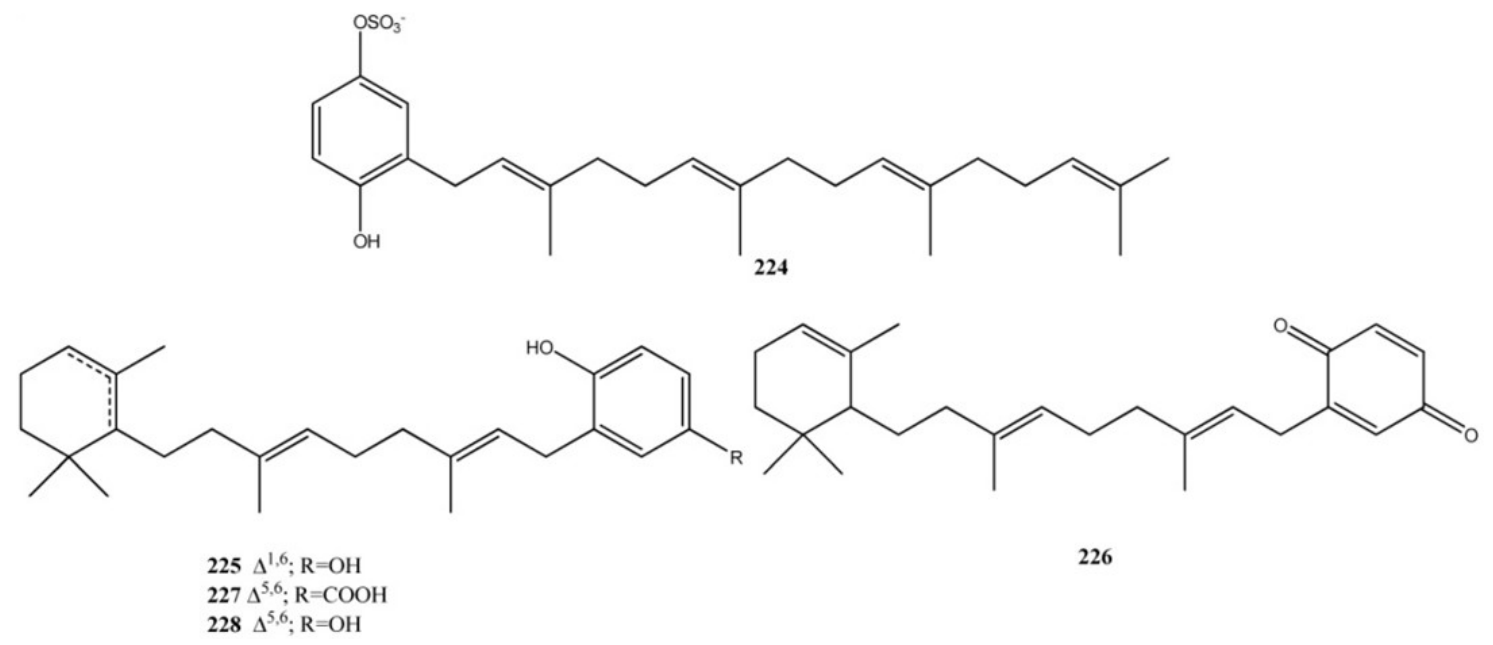

From extracts of two different sponges, Jaspis splendens (order Choristida, family Jaspidae) and Suberea sp. (order Verongida, family Aplysinellidae), collected in Papua New Guinea, mixed biogenesis bicyclic diterpene-benzenoid compounds, (-)-jaspic (229) and (-)-subersic (230) acids have been isolated (Figure 17) [163]. Both compounds 229 and 230 were active as human 15-lipoxygenase (15-hLO) inhibitors $\left(\mathrm{IC}_{50}\right.$ values between 0.3 and $\left.15.0 \mu \mathrm{M}\right)$ and 229 was also shown to inhibit 12-lipoxygenase $(12-\mathrm{hLO})\left(\mathrm{IC}_{50}=0.7 \pm 0.05\right)$. (+)-Isojaspic acid (231) has been isolated from Cacospongia sp. and it has shown a significant antimicrobial activity against $S$. epidermidis $(\mathrm{MIC}=2.5 \mu \mathrm{g} / \mathrm{mL})$ [161]. Interestingly, the enantiomer of the (-)-subersic acid (230), the (+)-subersic acid (232), isolated from Acanthodendrilla sp., inhibited the protein kinase MK2 with $\mathrm{IC}_{50}$ of $9.6 \mu \mathrm{M}[164]$.

Figure 17. Diterpene benzo(hydro)quinones with bicyclic terpene moieties.
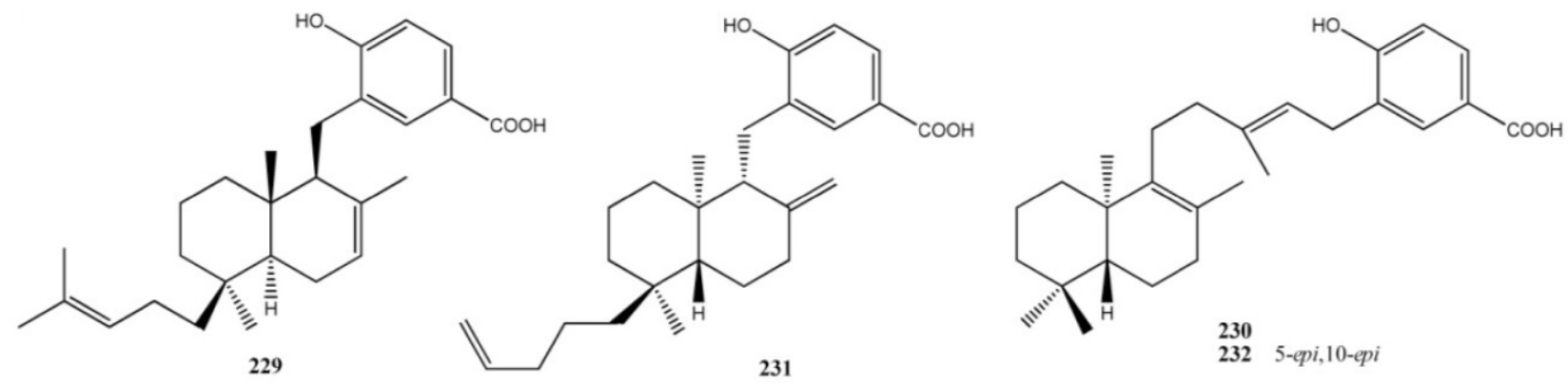

Chromane meroditerpenes (Figure 18) have been isolated from Psammocinia and Fasciospongia sp. Bioassay-guided fractionation of the active Psammocinia extract led to the isolation of a series of hLO inhibitory chromanes meroditerpenes named chromarols A-E (233-237) [165]. These compounds were tested in order to determine their comparative inhibition against 15-hLO and 12-hLO. The results of this analysis were quite remarkable, with chromarols A-D (233-236) exhibiting selective ( $>25-166$-fold) inhibition against 15 -hLO versus 12-hLO. Furthermore, 233-236 were relatively potent inhibitors of 15-hLO, exhibiting $\mathrm{IC}_{50}$ values ranging from $0.6 \pm 0.1$ to $4.0 \pm 0.5 \mu \mathrm{M}$. In stark contrast, the 6-carboxychromane derivative, chromarol E (237), exhibited no selectivity for either isozyme. Instead, 237 displayed comparable potency against both $15-\mathrm{hLO}$ and $12-\mathrm{hLO}\left(\mathrm{IC}_{50}=3.3 \pm 0.4\right.$ and $1.2 \pm 0.1 \mu \mathrm{M}$, 
respectively). A new metabolite, fascioquinol $\mathrm{F}$ (238), with a structure comparable to those of chromarols, has been isolated from Fasciospongia sp. [156].

Figure 18. Chromane meroditerpenes.
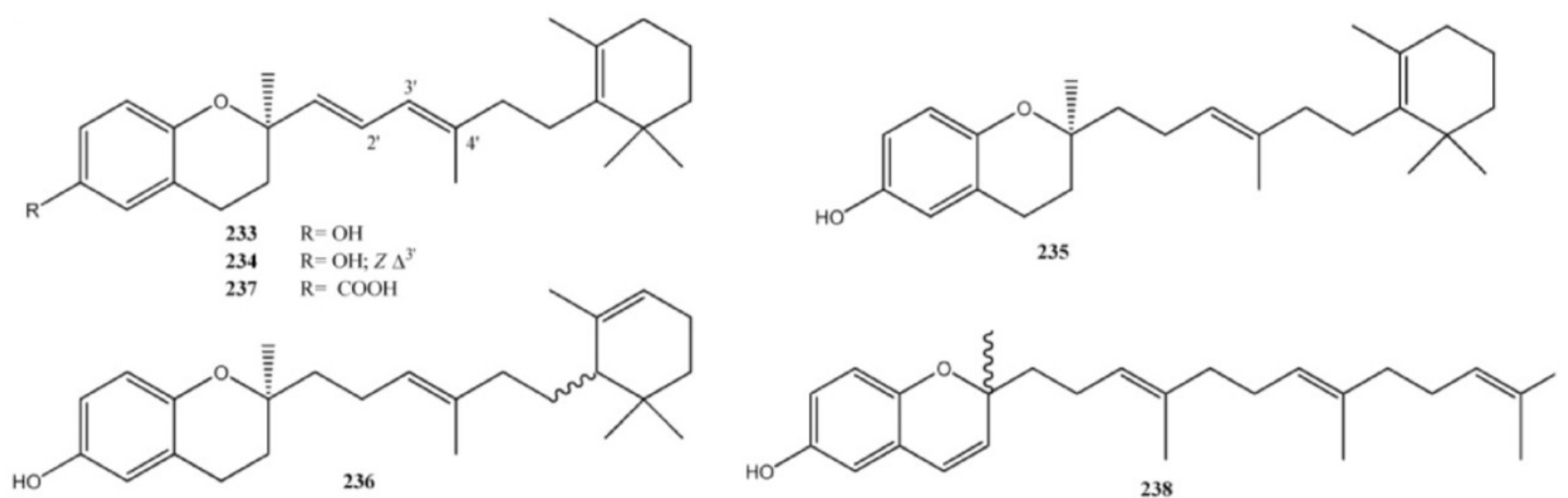

The screen of marine sponges Acanthodendrilla sp. and Fasciospongia sp. led to isolation of diterpene benzo(hydro)quinones with tricyclic terpene moieties (Figure 19). The extract of Acanthodendrilla sp., collected in Indonesia, led to the isolation of (+)-makassaric acid (239) which also is an inhibitor of the protein kinase $\mathrm{MK} 2$ with an $\mathrm{IC}_{50}$ 's value of $20 \mu \mathrm{M}$ [164]. Chemical investigation of a southern Australian deep-water marine sponge, Fasciospongia sp., returned the new meroterpene sulfate fascioquinol A (240) together with its desulfated analog, fascioquinol B (241). Both compounds 240 and 241 displayed a promising Gram-positive selective antibacterial activity towards Staphylococcus aureus $\left(\mathrm{IC}_{50} 0.9-2.5 \mu \mathrm{M}\right)$ and Bacillus subtilis $\left(\mathrm{IC}_{50} 0.3-7.0 \mu \mathrm{M}\right)$ [156].

Figure 19. Diterpene benzo(hydro)quinones with tricyclic terpene moieties.

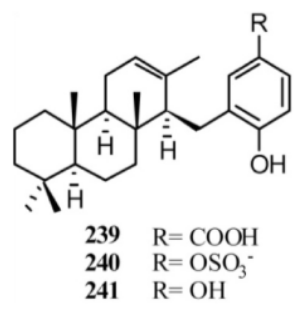

Meroditerpenoids with more complex structures featuring further oxygen spiranic or dihydropyranic rings, are strongylophorines (242-262) (Figure 20), first reported from the sponge Strongylophora durissima collected in Papua New Guinea [166] and in the Philippines [167]. Strongylophorines exhibited several biological activities including antimicrobic and insecticidal activities, lethal toxicity to brine shrimp, and inhibition of the maturation of starfish oocytes [168-172]. Strongylophorines-8 (247) and -26 (262) were found to have potent antiinvasive activity using MDA-MB-231 breast cancer cells [173], whereas the strongylophorines 2 (243), 3 (244), and 8 (247) inhibited the HIF-1-dependent luciferase expression in U251-HRE cells with $\mathrm{EC}_{50}$ values much lower than their cytotoxic concentrations [174]. In addition, further studies have shown that strongylophorine-8 (247) activated the Nrf2/ARE pathway and protected neuronal cells against oxidative stress, representing the first example of a neuroprotective pro-electrophilic compound from marine organisms [175]. Related to strongylophorines are fascioquinols C (263) and D (264), isolated from Fasciospongia sp. [156]. 
Figure 20. Strongylophorines and fascioquinols C and D.
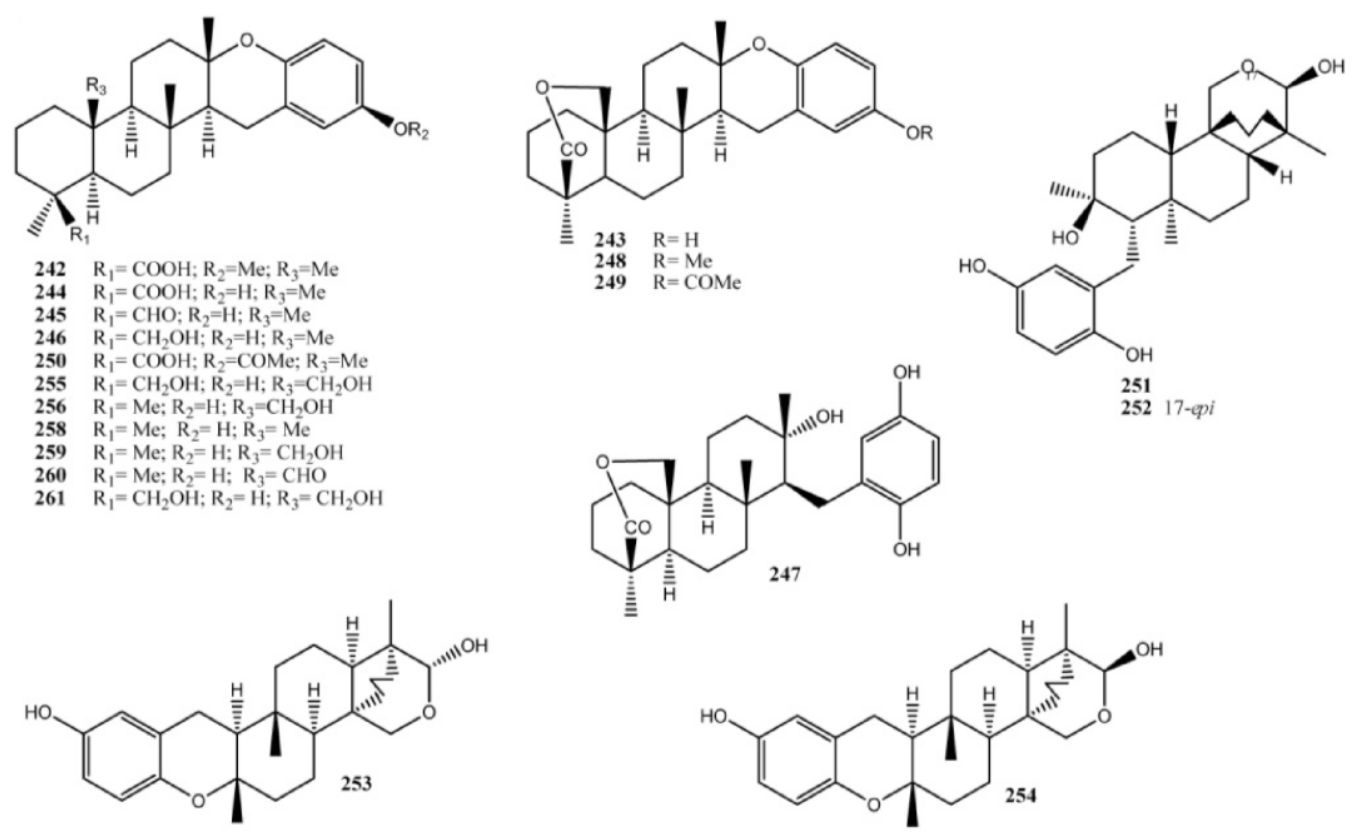

251
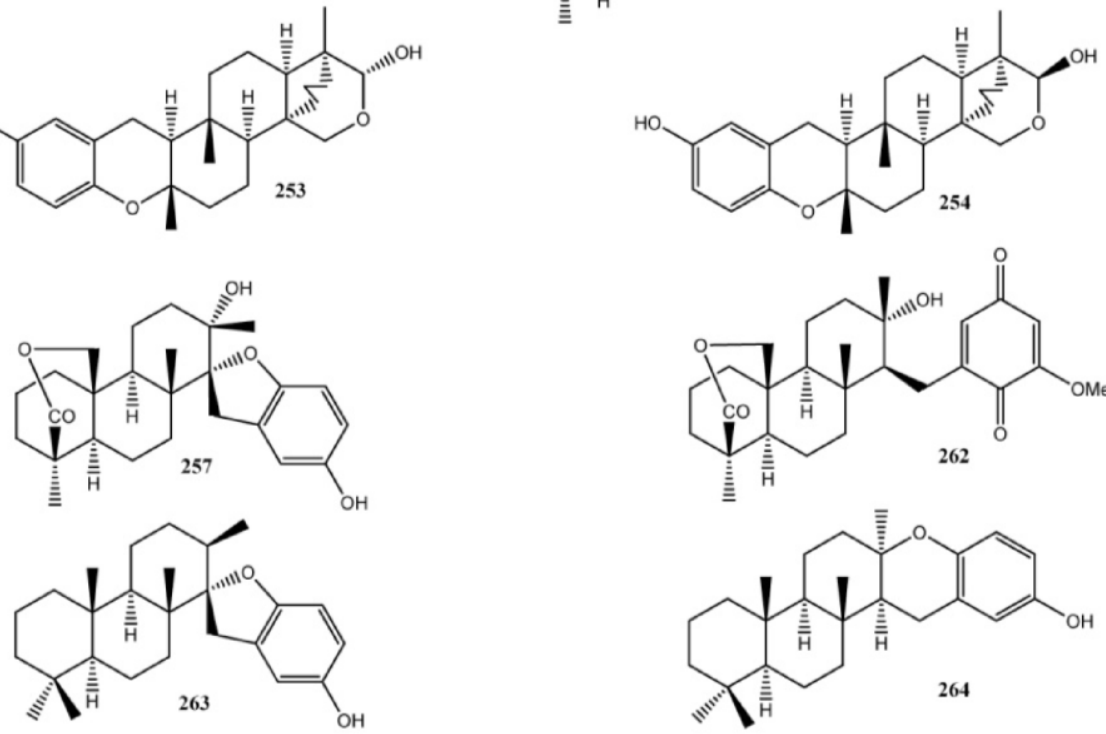

Coscinoquinol (265), its isomer 266, and the related sulfate-containing compounds halisulfates and coscinosulfates (267-271) (Figure 21) are examples of sestermeroterpenes [176-179]. Halisulfates and coscinoquinols have been reported to possess diverse bioactivities: cytotoxicity, antimicrobial activity, and inhibitory activities against isocitrate lyase, phospholipase A2, serine protease, phosphatase, and PMA-induced inflammation [177-183]. Significant structure-activity relationships have been evidenced in this compounds family. Compounds 265, 267 and 269 were active (MIC 1.56-25 $\mu \mathrm{g} / \mathrm{mL}$ ) against Gram-positive (Bacillus subtilis, Micrococcus luteus, and Staphylococcus aureus) and/or -negative (Proteus vulgaris and Salmonella typhimurium) bacteria. Interestingly, despite the significant inhibition shown by halisulfate 1 (267), its isomer 268 displayed no antibacterial activity at all. This same phenomenon was observed between coscinoquinol (265) and its isomer (266). Coscinoquinols (265 and 266) were also cytotoxic against the $K 562$ cell line, showing more potent inhibition than doxorubicin, while the halisulfates with hydroquinone moiety (267-269) were inactive. In enzyme-based assays, compounds 267-269, exhibited significant inhibition of sortase A, a key enzyme for the cell adhesion of Gram-positive bacteria; this activity was related to the presence of both hydroquinone and sulfate functionalities. In an assay against Candida albicans-derived isocitrate lyase (ICL), an enzyme of the glyoxylate cycle in microorganisms, the coscinoquinols were inactive, while all other sulfate-containing compounds displayed moderate to significant inhibition. A similar trend was observed for the 
$\mathrm{Na}+/ \mathrm{K}+$-ATPase inhibitory assay, in which more potent activities were found for the sulfate-containing compounds (267-268) than the coscinoquinols (265 and 266) [176]. Coscinosulfate (270) displayed significant inhibitory activity towards CDC25A phosphatase with an $\mathrm{IC}_{50}$ of $3 \mu \mathrm{M}$, while its analog (271) was less active $\left(\mathrm{IC}_{50}\right.$ value of $\left.18 \mu \mathrm{M}\right)$ [184]. Both compounds 270 and 271 showed also an antimicrobial activity towards $S$. aureus with inhibition zones, respectively: $12 \mathrm{~mm}(50 \mu \mathrm{g} / \mathrm{disk})$ and $10 \mathrm{~mm}(100 \mu \mathrm{g} / \mathrm{disk})$ [179].

Figure 21. Sestermeroterpenes: coscinoquinols, coscinosulfates, and halisulfates.
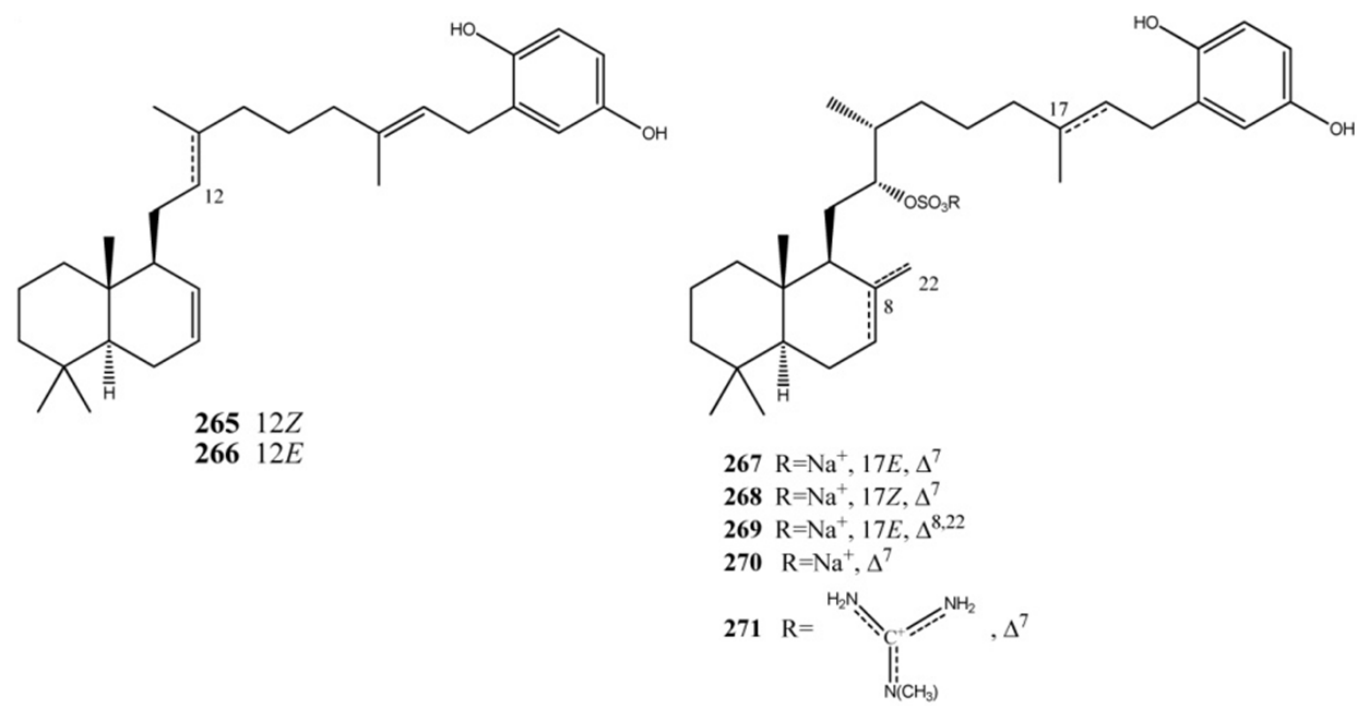

Examples of hexaprenoid hydroquinones are reported in Figure 22. The sulfated compounds toxiusol (272), shaagrockol B (273), shaagrockol C (274), toxicol A (275), toxicol B (276), the p-hydroquinone derivative of compound 275, and toxicol C (277), isolated from Toxiclona toxius [185,186], are of interest not only because of their structures but also because of their biological properties, which includes an important activity against human immunodeficiency virus type 1 (HIV-1) reverse transcriptase (RT). The hydrolysis of compounds 272 and 274 yielded the corresponding hydroquinones designated as compounds $\mathbf{2 7 8}$ and $\mathbf{2 7 9}$, and further oxidation of compound $\mathbf{2 7 6}$ afforded the corresponding p-quinone derivative. Compounds 272-276, 278 and 279 exhibited inhibitory activity of both DNA polymerizing functions of HIV-1 RT but failed to inhibit the RT-associated ribonuclease $\mathrm{H}$ activity [74]. The sponges of the genus Adocia (order Haplosclerida, family Chalinidae), collected in different places, also are the source of biologically active hexaprenoid hydroquinone sulfates (Figure 22) [187-191]. From the crude extract of Haliclona (aka Adocia) sp., collected at Palau, it has been possible to isolate adociasulfates 1-6 (280-285) [187], which contain mono- or di-sulfated hydroquinones, and adociasulfate 10 (286) (Figure 22) [188], in which there is an unusual glycolic acid residue in place of one of the sulfates groups. These compounds are inhibitor of the kinesin family of microtubule proteins, a group of proteins that transport cargo along the microtubules within the cells $[192,193]$. Adociasulfate $10(\mathbf{2 8 6})$ had an $\mathrm{IC}_{50}$ of $7 \mu \mathrm{M}$, which is almost identical to the activity of adociasulfate $2(\mathbf{2 8 1}), \mathrm{IC}_{50}$ of $6 \mu \mathrm{M}$. It is interesting to note that substitution of one sulfate group by the glycolic acid moiety of adociasulfate 10 (286) does not significantly reduce its inhibition of kinesin motors. Independently, adociasulfates 1 (280), 7 (287), and 8 (288), isolated from an unidentified species of Adocia collected in Northern Queensland, were found to have $\mathrm{H}^{+}$-ATPase protein pump 
activity [189]. A further investigation of a Palauan specimen of Haliclona led to the isolation of three new merotriterpenoids, adociaquinol (289), adociasulfates 11 (290) and 12 (291) [190], whereas an investigation of a sample of Adocia aculeata collected from Cormorant Pass, North Great Barrier Reef, led to the isolation of a new triterpene hydroquinone sulfate, adociasulfate 9 (292) [191]. Two new terpene-ketides, haliclotriol A (293) and haliclotriol B (294), have been isolated from two Indo-Pacific members of Aciona genus [194]. The major structure of haliclotriols A (293) and B (294) is derived from the cyclization of a hexaprenoid precursor. The biological activity properties of the triterpenes were investigated: a weak antimicrobial activity was observed for haliclotriol B (294) at $1 \mathrm{mg}$ disk against B. subtilis and S. aureus, respectively.

Figure 22. Sulfated triterpene hydroquinones.

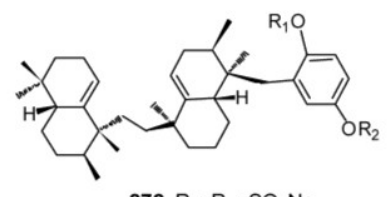

$272 \mathrm{R}_{1}=\mathrm{R}_{2}=\mathrm{SO}_{3} \mathrm{Na}$ $278 \mathrm{R}_{1}=\mathrm{R}_{2}=\mathrm{H}$
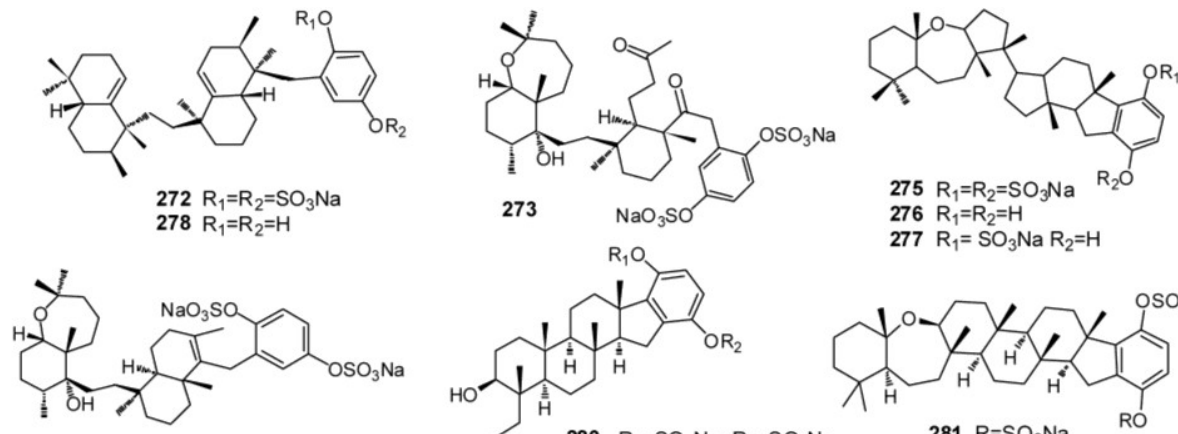

$277 \mathrm{R}_{1}=\mathrm{SO}_{3} \mathrm{Na} \mathrm{R}=\mathrm{H}$
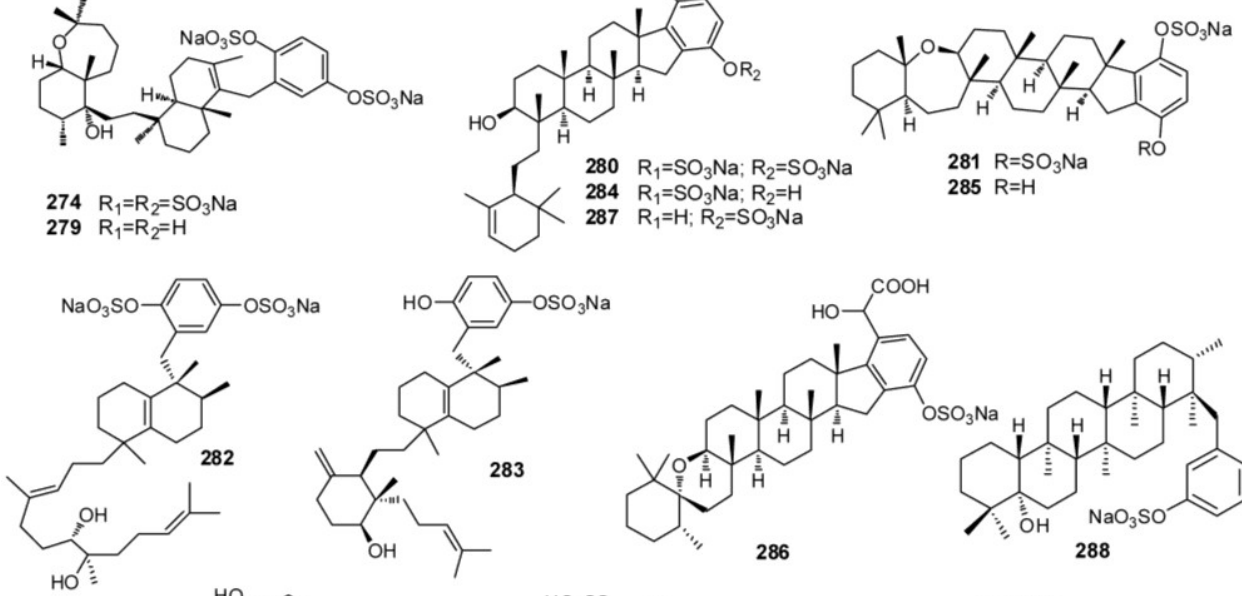
$285 \mathrm{R}=\mathrm{H}$
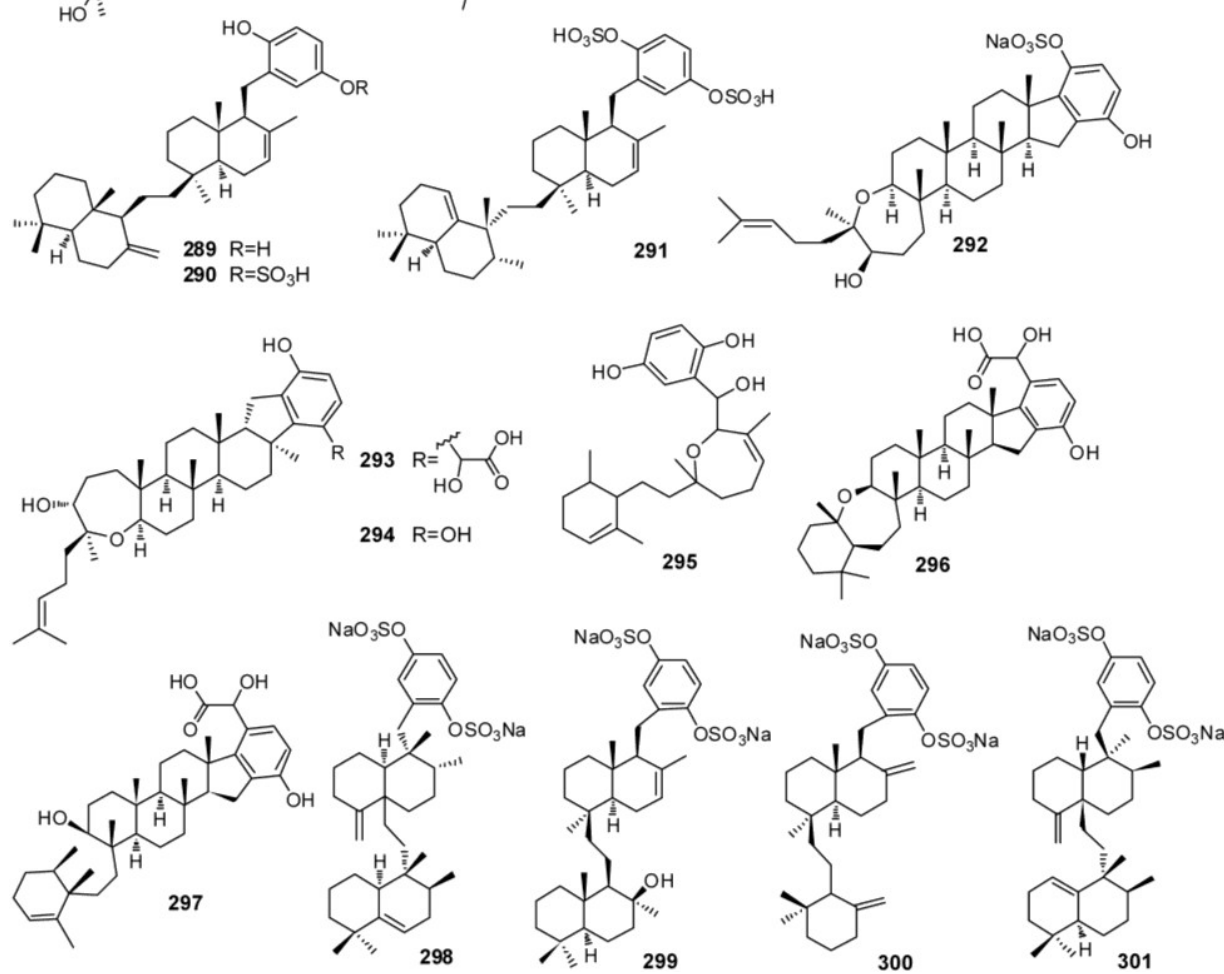
Halioxepine (295), from an Indonesian sample of Haliclona sp. [195] showed moderate cytotoxicity against NBT-T2 cells with $\mathrm{IC}_{50} 4.8 \mu \mathrm{g} / \mathrm{mL}$ and it also exhibited antioxidant activity against 1,1-diphenyl-2-picrylhydrazyl (DPPH) with $\mathrm{IC}_{50} 3.2 \mu \mathrm{g} / \mathrm{mL}$ as well as other hydroquinone-containing meroditerpenes [196]. Halicloic acids A (296) and B (297), isolated from a sample of Haliclona collected in the Philippines [197], are related to the known compounds adociasulphates 2 (281) [187] and 10 (286) [188] and haliclotriol A (293) [194]. Bioassay-guided fractionation of the extract identified halicloic acids A (296) and B (297) as indoleamine 2,3-dioxygenase inhibitors. Akaterpin (298), isolated from the marine sponge Callyspongia sp. having disulfated hydroquinone moiety, is an inhibitor of phosphatidylinositol-specific phospholipase $\mathrm{C}$ with an $\mathrm{IC}_{50}$ value of $0.5 \mu \mathrm{g} / \mathrm{mL}$. It also inhibits neutral sphingomyelinase weakly with an $\mathrm{IC}_{50}$ of $30 \mu \mathrm{g} / \mathrm{mL}$ [198]. Three new disulfated meroterpenoids, ilhabelanol (299), ilhabrene (300), both with unprecedented meroterpenoid carbon skeletons, and isoakaterpin (301), have been isolated from extracts of the same sponge (Figure 22). They are inhibitors of Leishmania spp. adenosine phosphoribosyl transferase (APRT), an important component of the purine salvage pathway in the parasites [199].

\section{Meroterpenes from Soft Corals}

A limited number of meroterpenoids have been isolated from soft corals, the only examples being the geranyl idroquinone derivatives 302-304 isolated from the marine octocoral Alcyonium fauri [200] and the meroditerpenois 305-314 isolated from Nephthea chabrolii [201-203] (Figure 23).

Figure 23. Meroterpenoids from soft corals.
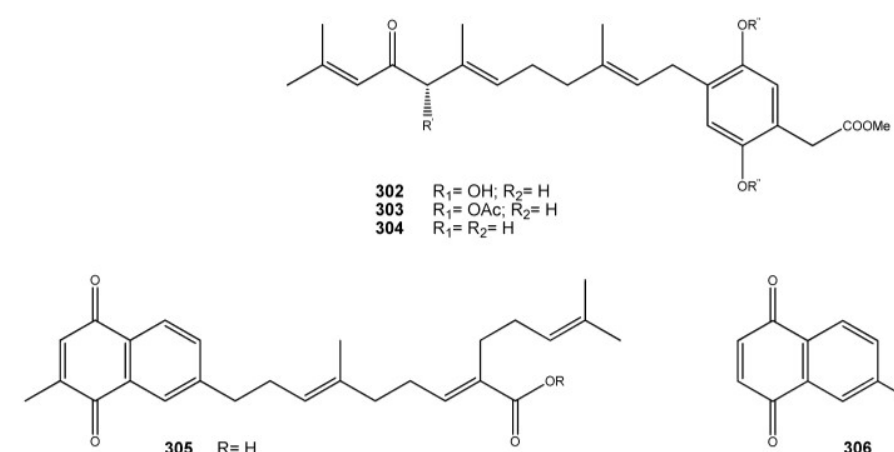

$\begin{array}{ll}305 & \mathrm{R}=\mathrm{H} \\ 307 & \mathrm{R}=\mathrm{Me}\end{array}$

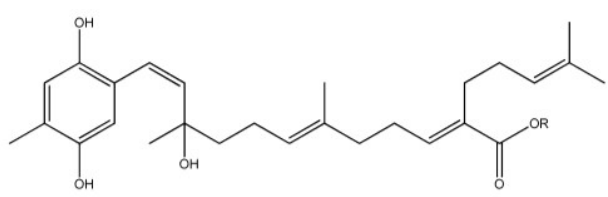

$\begin{array}{ll}308 & R=H \\ 309 & R=M e\end{array}$
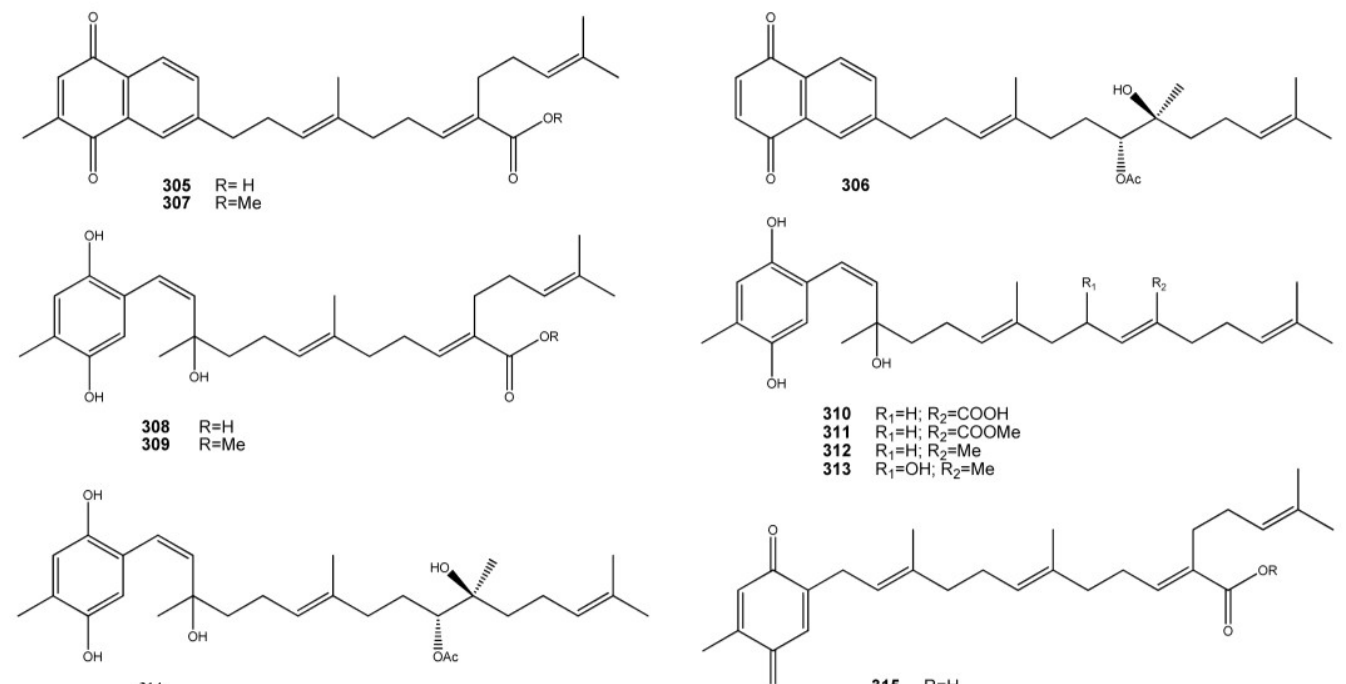

$\begin{array}{ll}310 & R_{1}=H ; \\ 311 & R_{2}=\mathrm{COOH} \\ R_{1}=H ; R_{2}=\mathrm{COOMe}\end{array}$

$\begin{array}{ll}311 & R_{1}=H ; R_{2}=C O O M \\ 312 & R_{1}=H ; R_{2}=M e \\ 313 & R_{1}=O H ; R_{2}=M e\end{array}$
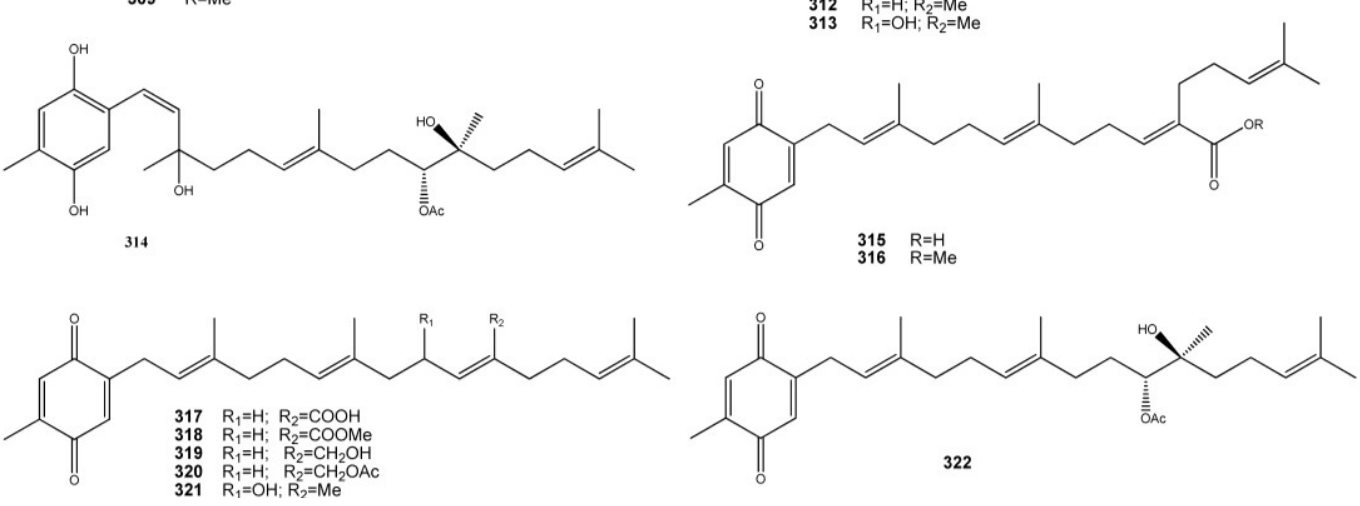
In a NCI's CEM-SS cell line screen, designed to detect agents acting at any stage in the HIV virus reproductive cycle, rietone (302) showed moderate activity $\left(\mathrm{EC}_{50} 1.23 \mu \mathrm{M}\right.$ and $\left.\mathrm{IC}_{50} 9.32 \mu \mathrm{M}\right)$ [200]. $N$. chabrolii metabolites series include the naphthoquinone derivatives chabrolonaphthoquinone A-C (305-307), the tetraprenyltoluquinol-related metabolites chabrolohydroxybenzoquinones A- G (308-314), and the tetraprenyltoluquinones chabrolobenzoquinones $\mathrm{A}-\mathrm{H}$ (315-322). Compound 306 exhibited significant cytotoxicity against the growth of the MDA-MB-231 $\left(\mathrm{IC}_{50} 4.7 \mu \mathrm{M}\right)$ cancer cell line and moderate to weak cytotoxicity against Hep $\mathrm{G} 2\left(\mathrm{IC}_{50} 12.4 \mu \mathrm{M}\right)$ and $\mathrm{A} 549\left(\mathrm{IC}_{50} 33.9 \mu \mathrm{M}\right)$ cancer cell lines, respectively. Also, metabolites $\mathbf{3 0 7}$ and $\mathbf{3 1 4}$ exhibited moderate to weak cytotoxicity toward these cancer cells. Other metabolites either were inactive or exhibit only weak cytotoxicity against the growth of the above three cancer cell lines.

\section{Conclusive Remarks}

The great chemical diversity generating in the group of meroterpenes isolated from marine invertebrates and their wide range of biological activities represent a useful tool for development of new therapeutics. But the biomedical potential of these compounds could be greatly enhanced by a comprehensive understanding of their biosynthetic origin combined with the recent progress in molecular biology. The occurrence of different but biosynthetically related meroterpenes in different organisms, in terrestrial sources, and/or in collections of the same organism from distinct geographical locations, strongly supports the possibility of their biosynthesis by associated microorganisms. Significantly, several meroterpenoids have been recently isolated from Aspergillus spp. derived from tissues of marine invertebrates. It is known that members of the genus Aspergillus can combine polyketide and terpene precursors to produce meroterpenoids, some of whom having important relevance to human health; this is the case of territrem $\mathrm{B}$, produced by A. terreus, a potent irreversible inhibitor of acetyl cholinesterase (AChE) and a candidate for drug development for treating Alzheimer's disease [204]. Examples of meroterpenoids isolated from invertebrate-associated Aspergillus spp. are tropolactones A-D (323-326) isolated from an Aspergillus sp. derived from an unidentified sponge [205], insuetolides A-C (327-329) from A. insuetus isolated from the Mediterranean sponge Psammocinia sp. [206], terretonins E (330) and $\mathrm{F}$ (331), isolated from $A$. insuetus derived from the Mediterranean sponge Petrosia ficiformis [207], austalides M-Q (332-336) from an Aspergillus sp. derived from the sponge Tethya aurantium [208], and yanuthones (337-344) isolated from A.niger obtained from tissue homogenates of an Aplidium ascidian [209] (Figure 24). Thus, there are grounds to suppose that meroterpenoids isolated from marine invertebrates or, at least, portions of their structure are microbial products, most likely elaborated by Aspergillus fungi. If confirmed, this possibility could work to advantage the research on these compounds, both for the exploitation of their huge chemical diversity and for a potential large-scale production of the bioactive molecules. The Aspergillus genus of fungi, indeed, has been largely investigated due to its medical and commercial importance. Research on Aspergillus has contributed much knowledge about its fundamental cell biology and biochemistry and, foremost, the significance of Aspergillus was cause for the sequencing of the genomes of some of the most well-known members of this genus which are now publicly available [210]. Attempts to locate the biosynthetic genes for meroterpenoids production in the genome of some Aspergillus spp. have been performed with encouraging results; the biosynthetic pathway for some meroterpenoids (austinol, 
terretonin) has been proposed [211,212]. Understanding of Aspergillus secondary metabolism would greatly profit from the genome sequencing projects; sequence information greatly facilitates the identification of natural product genes, the function of which can be demonstrated by molecular biological and biochemical approaches. When a set of genes involved in the formation of the same secondary metabolite are recognized, a biosynthesis can be proposed. Down the road, such advances should be useful for enhanced production of secondary metabolites of interest and the development of second-generation compounds with improved pharmacodynamic and pharmacokinetic characteristics. Thus, advances in Aspergillus secondary metabolite research in the post-genomic era will bring an understanding of meroterpenoids biosynthesis at the genetic level which should facilitate engineering of second generation molecules and increasing production of first generation compounds.

Figure 24. Meroterpenoids from marine invertebrates-associated Aspergillus spp.
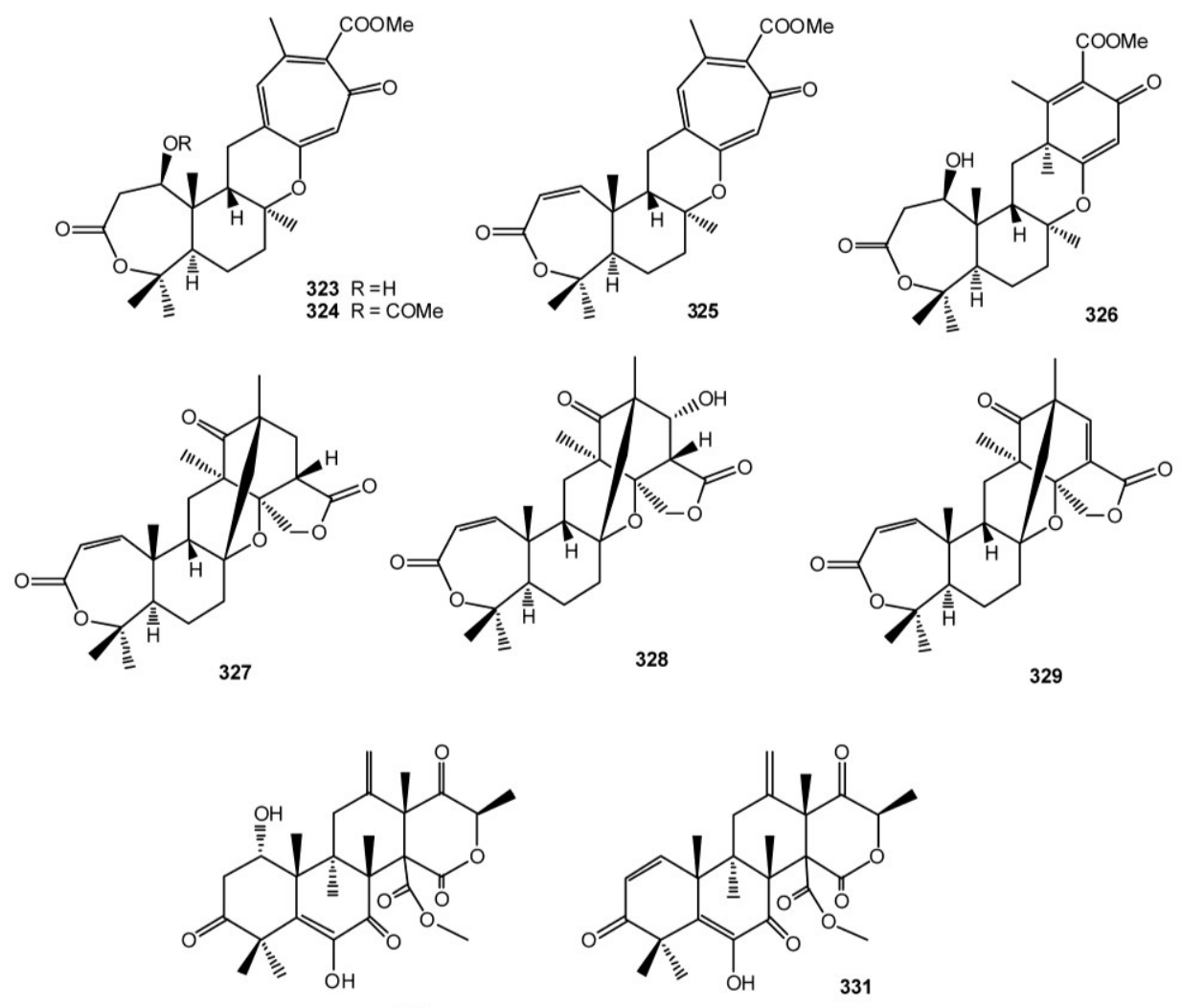

330
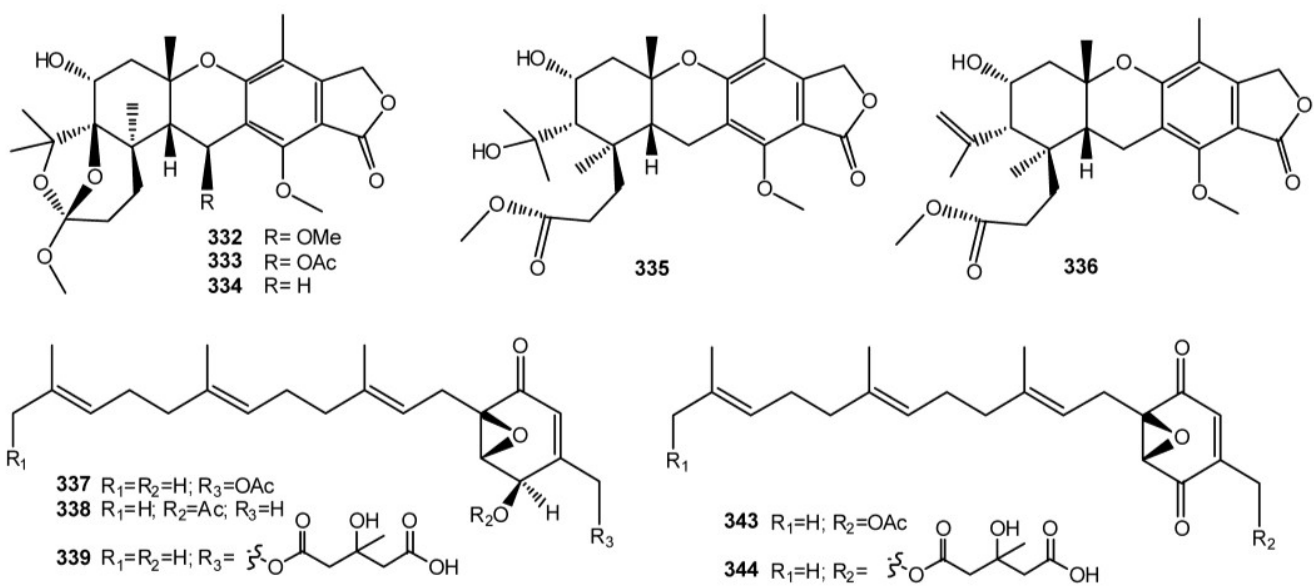

$340 \mathrm{R}_{1}=\mathrm{OH} ; \mathrm{R}_{2}=\mathrm{H} ; \mathrm{R}_{3}=\mathrm{OAC}$ 


\section{Acknowledgments}

This work was supported by the European Commission through the FP7 Projects no. 229893 (NatPharma) and 311848 (BlueGenics), and by the Italian Ministero dell'Università e della Ricerca (MIUR) (PRIN2009: Sostanze naturali ed analoghi sintetici in grado di interferire con target biologici coinvolti nel controllo della crescita tumorale).

\section{Conflict of Interest}

The authors declare no conflict of interest.

\section{References}

1. Thomson, R.H. Naturally Occurring Quinones, 2nd ed.; Academic Press: London, UK, 1971; pp. 93-197.

2. Pennock, J.F. Terpenoids in Plants; Pridham, J.B., Ed.; Academic Press: London, UK, 1967; pp. 129-146.

3. Monks, T.J.; Hanzlik, R.P.; Cohen, G.M.; Ross, D.; Graham, D.G. Quinone chemistry and toxicity. Toxicol. Appl. Pharmacol. 1992, 112, 2-16.

4. O'Brien, P.J. Molecular mechanisms of quinone cytotoxicity. Chem. Biol. Interact. 1991, 80, $1-41$.

5. Zubìa, E.; Ortega, M.; Salvà, J. Natural products chemistry in marine ascidians of the genus Aplidium. Mini Rev. Org. Chem. 2005, 2, 546-564.

6. Menna, M.; Fattorusso, E.; Imperatore, C. Alkaloids from marine ascidians. Molecules 2011, 16, 8694-8732.

7. Menna, M.; Aiello, A. The Chemistry of Marine Tunicates. In Handbook of Marine Natural Products; Fattorusso, E., Gerwick, W.H., Taglialatela-Scafati, O., Eds.; Springer Science + Business Media: New York, NY, USA, 2012; Volume 1, pp. 295-385.

8. Fenical, W. Geranyl hydroquinone, a cancer-protective agent from the tunicate Aplidium species. Food Drugs Sea Proc. 1976, 4, 388-394.

9. Sato, A.; Shindo, T.; Kasanuki, N.; Hasegawa, K. Antioxidant metabolites from the tunicate Amaroucium multiplicatum. J. Nat. Prod. 1989, 52, 975-981.

10. Aknin, M.; Dayan, T.L.A.; Rudi, A.; Kashman, Y.; Gaydou, E.M. Hydroquinone antioxidants from the Indian Ocean tunicate Aplidium savignyi. J. Agric. Food Chem. 1999, 47, 4175-4177.

11. Garrido, L.; Zubía, E.; Ortega, M.J.; Salvá, J. New meroterpenoids from the ascidian Aplidium conicum. J. Nat. Prod. 2002, 65, 1328-1331.

12. Shubina, L.K.; Fedorov, S.N.; Radchenko, O.S.; Balaneva, N.N.; Kolesnikova, S.A.; Dmitrenok, P.S.; Bode, A.; Dong, Z.; Stonik, V.A. Desmethylubiquinone Q2 from the far-eastern ascidian Aplidium glabrum: Structure and synthesis. Tetrahedron Lett. 2005, 46, 559-562.

13. Chan, S.T.S.; Pearce, A.N.; Januario, A.H.; Page, M.J.; Kaiser, M.; McLaughlin, R.J.; Harper, J.L.; Webb, V.L.; Barker, D.; Copp, B.R. Anti-inflammatory and antimalarial meroterpenoids from the New Zealand ascidian Aplidium scabellum. J. Org. Chem. 2011, 76, 9151-9156. 
14. Guella, G.; Mancini, I.; Pietra, F. Verapliquinones: Novel diprenylquinones from an Aplidium sp. (Ascidiacea) of Ile-Verte waters, Brittany. Helv. Chim. Acta 1987, 70, 621-626.

15. Appleton, D.R.; Chuen, C.S.; Berridge, M.V.; Webb, V.L.; Copp, B.R. Rossinones A and B, biologically active meroterpenoids from the Antarctic ascidian, Aplidium species. J. Org. Chem. 2009, 74, 9195-9198.

16. Howard, B.M.; Clarkson, K. Simple prenylated hydroquinone derivatives from the marine urochordate Aplidium californicum natural anticancer and antimutagenic agents. Tetrahedron Lett. 1979, 46, 4449-4452.

17. Fedorov, S.N.; Radchenko, O.S.; Shubina, L.K.; Balaneva, N.N.; Bode, A.M.; Stonik, V.A.; Dong, Z. Evaluation of cancer-preventive activity and structure-activity relationship of 3-demethylubiquinone Q2, isolated from the ascidian Aplidium glabrum and its synthetic analogs. Pharm. Res. 2006, 23, 70-81.

18. Fedorov, S.N.; Radchenko, O.S.; Shubina, L.K.; Balaneva, N.N.; Agafonova, I.G.; Bode, A.M.; Jin, J.O.; Kwak, J.Y.; Dong, Z.; Stonik, V. Anticancer activity of 3-demethylubiquinone Q2. In vivo experiments and probable mechanism of action. Anticancer Res. 2008, 28, 927-932.

19. Laird, D.W.; Poole, R.; Wikstroem, M.; van Altena, I.A. Pycnanthuquinone C, an unusual 6,6,5-tricyclic geranyltoluquinone from the western australian brown alga Cystophora harveyi. J. Nat. Prod. 2007, 70, 671-674.

20. Lumb, J.P.; Trauner, D. Pericyclic reactions of prenylated naphthoquinones: Biomimetic syntheses of mollugin and microphyllaquinone. Org. Lett. 2005, 7, 5865-5868.

21. Morimoto, S.; Komatsu, K.; Taura, F.; Shoyama, Y. Purification and characterization of cannabichromenic acid synthase from Cannabis sativa. Phytochemistry 1998, 49, 1525-1529.

22. Simon-Levert, A.; Arrault, A.; Bontemps-Subielos, N.; Canal, C.; Banaigs, B. Meroterpenes from the ascidian Aplidium aff. densum. J. Nat. Prod. 2005, 68, 1412-1415.

23. Simon-Levert, A.; Aze, A.; Bontemps-Subielos, N.; Banaigs, B.; Genevière, A.M. Antimitotic activity of methoxyconidiol, a meroterpene isolated from an ascidian. Chem. Biol. Interact. 2007, $168,106-116$.

24. Targett, N.M.; Keeran, W.S. A terpenehydroquinone from the marine ascidian Aplidium constellatum. J. Nat. Prod. 1984, 47, 556-557.

25. Rochfort, S.J.; Metzger, R.; Hobbs, L.; Capon, R.J. New chromenols from a southern Australian tunicate Aplidium solidum. Aust. J. Chem. 1996, 49, 1217-1219.

26. Carrol, A.R.; Bowden, B.F.; Coll, J.C. Studies of Australian ascidians. III. A new tetrahydrocannabinol derivative from the ascidian Synoicum costellatum. Aust. J. Chem. 1993, 46, 1079-1083.

27. Choi, H.; Hwang, H.; Chin, J.; Kim, E.; Lee, J.; Nam, S.J.; Lee, B.C.; Rho, B.J.; Kang, H. Tuberatolides, potent FXR antagonists from the korean marine tunicate Botryllus tuberatus. J. Nat. Prod. 2011, 74, 90-94.

28. Davis, R.A.; Carroll, A.R.; Quinn, R.J. Longithorols C-E. Three new macrocyclic sesquiterpene hydroquinone metabolites from the Australian ascidian Aplidium longithorax. J. Nat. Prod. 1999, $62,1405-1409$. 
29. Carbone, M.; Nunez-Pons, L.; Paone, M.; Castelluccio, F.; Avila, C.; Gavagnin, M. Rossinone-related meroterpenes from the Antarctic ascidian Aplidium fuegiense. Tetrahedron 2012, 68, 3541-3544.

30. Fort, D.M.; Ubillas, R.P.; Mendez, C.D.; Jolad, S.D.; Inman, W.D.; Carney, J.R.; Chen, J.L.; Ianiro, T.T.; Hasbun, C.; Bruening, R.C.; et al. Novel antihyperglycemic terpenoid-quinones from Pycnanthus angolensis. J. Org. Chem. 2000, 65, 6534-6539.

31. Zhang, Z.; Chen, J.; Yang, Z.; Tang, Y. Rapid biomimetic total synthesis of $( \pm)$-rossinone B. Org. Lett. 2010, 12, 5554-5557.

32. Fu, X.; Hossain, M.B.; van der Helm, D.; Schmitz, F.J. Longithorone A: Unprecedented dimeric prenylated quinone from the Tunicate Aplidium longithorax. J. Am. Chem. Soc. 1994, 116, 12125-12126.

33. Fu, X.; Hossain, M.B.; Schmitz, F.J.; van der Helm, D. Longithorones, unique prenylated para- and metacyclophane type quinones from the Tunicate Aplidium longithorax. J. Org. Chem. 1997, 62, 3810-3819.

34. Davis, R.A.; Carroll, A.R.; Quinn, R.J. Longithorones J and K, two new cyclofarnesylated quinone derived metabolites from the Australian ascidian Aplidium longithorax. J. Nat. Prod. 1999, 62, 158-160.

35. Fu, X.; Ferreira, M.L.G.; Schmitz, F.J. Longithorols A and B, novel prenylated paracyclophane- and metacyclophane-tipe hydroquinones from the Tunicate Aplidium longithorax. J. Nat. Prod. 1999, 62, 1306-1310.

36. Kotha, S.; Shirbhate, M.E. Diversity-oriented approach to macrocyclic cyclophane derivatives via ring-closing metathesis. Synlett 2012, 23, 2183-2188.

37. Issa, H.H.; Tanaka, J.; Rachmat, R.; Higa, T. Floresolides, new metacyclophane hydroquinone lactones from an ascidian, Aplidium sp. Tetrahedron Lett. 2003, 44, 1243-1245.

38. Layton, M.E.; Morales, C.A.; Shair, M.D. Biomimetic synthesis of (-)-longithorone A. J. Am. Chem. Soc. 2002, 124, 773-775.

39. Aiello, A.; Fattorusso, E.; Luciano, P.; Menna, M.; Esposito, G.; Iuvone, T.; Pala, D. Conicaquinones A and B, two novel cytotoxic terpene quinones from the Mediterranean ascidian Aplidium conicum. Eur. J. Org. Chem. 2003, 2003, 898-900.

40. Aiello, A.; Fattorusso, E.; Luciano, P.; Mangoni, A.; Menna, M. Isolation and structure determination of aplidinones $\mathrm{A}-\mathrm{C}$ from the Mediterranean ascidian Aplidium conicum: A successful regiochemistry assignment by quantum mechanical 13C NMR chemical shift Calculations. Eur. J. Org. Chem. 2005, 2005, 5024-5030.

41. Aiello, A.; Fattorusso, E.; Luciano, P.; Macho, A.; Menna, M.; Muñoz, E. Antitumor effects of two novel naturally occurring terpene quinones isolated from the Mediterranean ascidian Aplidium conicum. J. Med. Chem. 2005, 48, 3410-3416.

42. Carbone, A.; Lucas, C.L.; Moody, C.J. Biomimetic synthesis of the apoptosis-inducing thiazinoquinone thiaplidiaquinone A. J. Org. Chem. 2012, 77, 9179-9189.

43. Khalil, I.M.; Barker, D.; Copp, B.R. Biomimetic synthesis of thiaplidiaquinones A and B. J. Nat. Prod. 2012, 75, 2256-2260. 
44. Aiello, A.; Fattorusso, E.; Luciano, P.; Menna, M.; Calzado, M.A.; Muñoz, E.; Bonadies, F.; Guiso, M.; Sanasi. M.F.; Cocco, G.; et al. Synthesis of structurally simplified analogues of aplidinone A, a pro-apoptotic marine thiazinoquinone. Bioorg. Med. Chem. 2010, 18, 719-727.

45. De Rosa, S.; de Giulio, A.; Iodice, C. Biological effects of prenylated hydroquinones: Structure-activity relationship studies in antimicrobial, brine shrimp, and fish lethality assays. J. Nat. Prod. 1994, 57, 1711-1716.

46. Muller, W.E.G.; Maidhof, A.; Zahn, R.K.; Schroder, H.C.; Gasic, M.J.; Heidemann, D.; Bernd, A.; Kurelec, B.; Eich, E.; Seibert, G. Potent antileukemic activity of the novel cytostatic agent avarone and its analogs in vitro and in vivo. Cancer Res. 1985, 45, 4822-4826.

47. Kondracki, M.L.; Guyot, M. Biologically active quinone and hydroquinone sesquiterpenoids from the sponge Smenospongia sp. Tetrahedron 1989, 45, 1995-2004.

48. Hamann, M.T.; Scheuer, P.J.; Kelly-Borges, M. Biogenetically diverse, bioactive constituents of a sponge, order Verongida: Bromotyramines and sesquiterpene-shikimate derived metabolites. J. Org. Chem. 1993, 58, 6565-6569.

49. Alvi, K.A.; Diaz, M.C.; Crews, P.; Slate, D.L.; Lee, R.H.; Moretti, R. Evaluation of new sesquiterpene quinones from two Dysidea sponge species as inhibitors of protein tyrosine kinase. J. Org. Chem. 1992, 57, 6604-6607.

50. Loya, S.; Tal, R.; Kashman, Y.; Hizi, A. Illimaquinone, a selective inhibitor of the RNase H activity of human immunodeficiency virus type 1 reverse transcriptase. Antimicrob. Agents Chemother. 1990, 34, 2009-2012.

51. Gordaliza, M. Cytotoxic terpene quinones from marine sponges. Mar. Drugs 2010, 8, 2849-2870.

52. Benites, J.; Valderrama, J.A.; Rivera, F.; Rojo, L.; Campos, N.; Pedro, M.; Nascimento, M.S.J. Studies on quinones. Part 42: Synthesis of furylquinone and hydroquinones with antiproliferative activity against human tumor cell lines. Bioorg. Med. Chem. 2008, 16, 862-868 and all previous parts.

53. Ishibashi, M.; Ohizumi, Y.; Cheng, J.-F.; Nakamura, H.; Hirata, Y.; Sasaki, T.; Kobayashi, J. Metachromins A and B, Novel antineoplastic sesquiterpenoids from the okinawan sponge Hippospongia cf. metachromia. J. Org. Chem. 1988, 53, 2855-2858.

54. Kobayashi, J.; Murayama, T.; Ohizumi, Y.; Ohta, T.; Nozoe, S.; Sasaki, T. Metachromin C, a new cytotoxic sesquiterpenoid from the okinawan marine sponge Hippospongia metachromia. J. Nat. Prod. 1989, 52, 1173-1176.

55. Kobayashi, J.; Naitoh, N.; Sasaki, T.; Shigemori, H. Metachromins D-H, new cytotoxic sesquiterpenoids from the okinawan marine sponge Hippospongia metachromia. J. Org. Chem. 1992, 57, 5773-5776.

56. Takahashi, Y.; Kubota, T.; Fromont, J.; Kobayashi, J. Metachromins L-Q, new sesquiterpenoid quinones with an aminoacid residue from sponge Spongia sp. Tetrahedron 2007, 63, 8770-8773.

57. Takahashi, Y.; Yamada, M.; Kubota, T.; Fromont, J.; Kobayashi, J. Metachromins R-T, new sesquiterpenoids from marine sponge Spongia sp. Chem. Pharm. Bull. 2007, 55, 1731-1733.

58. Ovenden, S.P.B.; Nielson, J.L.; Liptrot, C.H.; Willis, R.H.; Tapiolas, D.M.; Wright, A.D.; Motti, C.A. Metachromins U-W: Cytotoxic merosesquiterpenoids from an Australian specimen of the sponge Thorecta reticulata. J. Nat. Prod. 2011, 74, 1335-1338. 
59. Minale, L.; Riccio, R.; Sodano, G. Avarol, a novel sesquiterpenoid hydroquinone with a rearranged drimane skeleton from the sponge Disidea avara. Tetrahedron Lett. 1974, 38, 3401-3404.

60. Cimino, G.; de Rosa, S.; de Stefano, S.; Cariello, L.; Zanetti, L. Structure of two biologically active sesquiterpenoid amino-quinones from the marine sponge Dysidea avara. Experientia 1982, 38, 896.

61. De Rosa, S.; Minale, L.; Riccio, R.; Sodano, G. The absolute configuration of avarol, a rearranged sesquiterpenoid hydroquinone from a marine sponge. J. Chem. Soc. Perkin Trans. 1 1976, 1408-1414, doi:10.1039/P19760001408.

62. Giordano, F.; Puliti, R. Structure of the 2,5-dimethyl ether of avarol, a sesquiterpenoid hydroquinone from the marine sponge Dysidea avara. Acta Cryst. 1987, C43, 985-988.

63. Müller, W.E.G.; Sobel, C.; Sachsse, W.; Diehl-Seifert, B.; Zahn, R.K.; Eich, E.; Kljajić, Z.; Schröder, H.C. Biphasic and differential effects of the cytostatic agents avarone and avarol on DNA metabolism of human and murine T and B lymphocytes. Eur. J. Cancer Clin. Oncol. 1986, $22,473-476$.

64. Müller, W.E.G.; Sobel, C.; Diehl-Seifert, B.; Maidhof, A.; Schöder, H.C. Influence of the antileukemic and anti-human immunodeficiency virus agent avarol on selected immune responses in vitro and in vivo. Biochem. Pharmacol. 1987, 36, 1489-1494.

65. Cozzolino, R.; de Giulio, A.; de Rosa, S.; Strazzullo, G.; Gašič, M.J.; Sladić, D.; Zlatović, M. Biological activities of avarol derivatives, 1. Amino derivatives. J. Nat. Prod. 1990, 53, 699-702.

66. Sarin, P.S.; Sun, D.; Thornton, A.; Müller, W.E.G. Inhibition of replication of the etiologic agent of acquired immune deficiency syndrome (human T-lymphotropic retrovirus/ lymphadenopathy-associated virus) by avarol and avarone. J. Natl. Cancer Inst. 1987, 78, 663-666.

67. Schroeder, H.C.; Sarin, P.S.; Rottmann, M.; Wenger, R.; Maidhof, A.; Renneisen, K.; Muller, W.E.G. Differential modulation of host cell and HIV gene expression by combinations of Avarol and AZT in vitro. Biochem. Pharmacol. 1988, 37, 3947-3952.

68. Schroeder, H.C.; Wenger, R.; Gerner, H.; Reuter, P.; Kuchino, Y.; Sladic, D.; Muller, W.E.G. Suppression of the modulatory effects of the antileukemic and anti-human immunodeficiency virus compound avarol on gene expression by tryptophan. Cancer Res. 1989, 49, 2069-2076.

69. Schatton, W.; Schatton, M.; Pietschmamm, R. Method for the Preparation of Compositions with High Avarol Content from Sponge and Use for the Prevention and Treatment of Psoriasis and Tumors. Eur. Pat. Appl. EP 1391197 A1, 25 February 2004.

70. Iguchi, K.; Sahashi, A.; Khono, J.; Yamada, Y. New sesquiterpenoid hydroquinone and quinones from the Okinawan marine sponge (Dysidea sp.). Chem. Pharm. Bull. 1990, 38, 1121-1123.

71. Hirsch, S.; Rudi, A.; Kashman, Y.; Loya, Y. New avarone and avarol derivatives from the marine sponge Dysidea cinerea. J. Nat. Prod. 1991, 54, 92-97.

72. Crispino, A.; de Giulio, A.; de Rosa, S.; Strazzullo, G. A new bioactive derivative of avarol from the marine sponge Dysidea avara. J. Nat. Prod. 1989, 52, 646-648.

73. De Giulio, A.; de Rosa, S.; di Vincenzo, G.; Strazzullo, G. Further bioactive derivative of avarol from Dysidea avara. Tetrahedron 1990, 46, 7971-7976. 
74. Loya, S.; Tal, R.; Hizi, A.; Issacs, S.; Kashman, Y.; Loya, Y. Hexaprenoid hydroquinones, novel inhibitors of the reverse transcriptase of human immunodeficiency virus type 1. J. Nat. Prod. 1993, $56,2120-2125$.

75. Schmitz, F.J.; Lakshmi, V.; Powell, D.R.; van der Helm, D. Arenarol and arenarone: Sesquiterpenoids with rearranged drimane skeletons from the marine sponge Dysidea arenaria. J. Org. Chem. 1984, 49, 241-244.

76. Luibrand, R.T.; Erdman, T.R.; Vollmer, J.J.; Scheuer, P.J.; Finer, J.; Clardy, J. Ilimaquinone, a sesquiterpenoid quinone from a marine sponge. Tetrahedron 1979, 35, 609-612.

77. Liu, H.; Wang, G.; Namikoshi, M.; Kobayashi, H.; Yao, X.; Cai, G. Sesquiterpene quinones from a marine sponge Hippospongia sp. that inhibit maturation of starfish oocytes and induce cell cycle arrest with HepG2 cells. Pharm. Biol. 2006, 44, 522-527.

78. Cartè, B.; Rose, C.B.; Faulkner, D.J. 5-Epi-Ilimaquinone, a metabolite of the sponge Fenestraspongia sp. J. Org. Chem. 1985, 50, 2785-2787.

79. Kazlauskas, R.; Murphy, P.T.; Warren, R.G.; Wells, R.J.; Blount, J.F. New quinones from a dictyoceratid sponge. Aust. J. Chem. 1978, 31, 2685-2697.

80. Rodriguez, J.; Quinoa, H.; Riguera, R.; Peters, B.M.; Abrell, L.M.; Crews, P. The structures and stereochemistry of cytotoxic sesquiterpene quinones from Dactylospongia elegans. Tetrahedron 1992, 48, 6667-6680.

81. Capon, R.J.; MacLeod, J.K. Revision of the absolute stereochemistry of ilimaquinone. J. Org. Chem. 1987, 52, 5059-5060.

82. Nambiar, M.P.; Wu, H.C. Ilimaquinone inhibits the cytotoxicities of ricin, diphtheria toxin, and other protein toxins in Vero cells. Exp. Cell Res. 1995, 219, 671-678.

83. Takizawa, P.A.; Yucel, J.K.; Veit, B.; Faulkner, D.J.; Deerinck, T.; Soto, G.; Ellisman, M.; Malhotra, V. Complete vesiculation of Golgi membranes and inhibition of protein transport by a novel sea sponge metabolite, ilimaquinone. Cell 1993, 73, 1079-1090.

84. Casaubon, R.L.; Snapper, M.L. S-adenosylmethionine reverses ilimaquinone's vesiculation of the Golgi apparatus: A fluorescence study on the cellular interactions of ilimaquinone. Bioorg. Med. Chem. Lett. 2001, 11, 133-136.

85. Lu, P.-H.; Chueh, S.-C.; Kung, F.-L.; Pan, S.-L.; Shen, Y.-C.; Guh, J.-H. Illimaquinone, a marine sponge metabolite, displays anticancer activity via GADD153-mediated pathway. Eur. J. Pharmacol. 2007, 556, 45-54.

86. Guzmán, F.S.; Copp, B.R.; Mayne, C.L.; Concepcion, G.P.; Mangalindan, G.C.; Barrows, L.R.; Ireland, C.M. Bolinaquinone: A novel cytotoxic sesquiterpene hydroquinone from Philippine Dysidea sponge. J. Org. Chem. 1998, 63, 8042-804.

87. Li, Y.; Zhang, Y.; Shen, X.; Guo, Y. A novel sesquiterpene quinone from Hainan sponge Dysidea villosa. Bioorg. Med. Chem. Lett. 2009, 19, 390-392.

88. Jankam, A.; Somerville, M.J.; Hooper, J.N.A.; Brecknell, D.J.; Suksamrarna, A.; Garson, M.J. Dactylospongiaquinone, a new meroterpenoid from the Australian marine sponge Dactylospongia n. sp. Tetrahedron 2007, 63, 1577-1582. 
89. Yong, K.W.L.; Jankam, A.; Hooper, J.N.A.; Suksamrarn, A.; Garson, M.J. Stereochemical evaluation of sesquiterpene quinones from two sponges of the genus Dactylospongia and the implication for enantioselective processes in marine terpene biosynthesis. Tetrahedron 2008, 64, 6341-6348.

90. Utkina, N.K.; Veselova, M.V. New sesquiterpene quinones from marine sponges of the order Dictyoceratida. Chem. Nat. Compd. 1990, 26, 37-40.

91. Swersey, J.C.; Barrows, L.R.; Ireland, C.M. Mamanuthaquinone: An antimicrobial and cytotoxic metabolite of Fasciospongia sp. Tetrahedron Lett. 1991, 32, 6687-6690.

92. Talpir, R.; Rudi, A.; Kashman, Y.; Loya, Y.; Hizi, A. Three new sesquiterpene hydroquinones from marine origin. Tetrahedron 1994, 50, 4179-4184.

93. Poigny, S.; Huor, T.; Guyot, M.; Samadi, M. Synthesis of (-)-hyatellaquinone and revision of absolute configuration of naturally occurring (+)-hyatellaquinone. J. Org. Chem. 1999, 64, 9318-9320.

94. Bernet, A.; Schröder, J.; Seifert, K. Total synthesis of the marine sesquiterpene quinones hyatellaquinone and spongiaquinone. Helv. Chim. Acta 2003, 86, 2009-2020.

95. McNamara, C.E.; Larsen, L.; Perry, N.B.; Harper, J.L.; Berridge, M.V.; Chia, E.W.; Kelly, M.; Webb, V.L. Anti-inflammatory sesquiterpene-quinones from the New Zealand sponge Dysidea cf. cristagalli. J. Nat. Prod. 2005, 68, 1431-1433.

96. Coval, S.J.; Conover, M.A.; Mierzwa, R.; King, A.; Puar, M.S.; Phife, D.W.; Pai, J.K.; Burrier, R.E.; Ahn, H.S. Wiedendiol A and B, cholesteryl esther transfer protein inhibitors from marine sponge Xetospongia widenmayeri. Bioorg. Med. Chem. Lett. 1995, 5, 605-610.

97. Laube, T.; Bernet, A.; Dahse, H.-M.; Jacobsen, I.D.; Seifert, K. Synthesis and pharmacological activities of some sesquiterpene quinones and hydroquinones. Bioorg. Med. Chem. 2009, 17, 1422-1427.

98. Venkateswarlu, Y.; Faulkner, D.J.; Steiner, J.L.R.; Corcoran, E.; Clardy, J. Smenochromenes, unusual macrocyclic sesquiterpene hydroquinone derivatives from a Seychelles sponge of the genus Smenospongia. J. Org. Chem. 1991, 56, 6271-6274.

99. Goclik, E.; Konig, G.M.; Wright, A.D.; Kaminsky, R. Pelorol from the tropical marine sponge Dactylospongia elegans. J. Nat. Prod. 2000, 63, 1150-1152.

100. Sullivan, B.; Djura, P.; McIntyre, D.E.; Faulkner, D.J. Antimicrobial constituents of the sponge Siphonodictyon coralliphagum. Tetrahedron 1981, 37, 979-982.

101. Sullivan, B.; Faulkner, D.J.; Matsumoto, G.K.; He, C.H.; Clardy, J. Metabolites of the burrowing sponge Siphonodictyon coralliphagum. J. Org. Chem. 1986, 51, 4568-4573.

102. Grube, A.; Assmann, M.; Lichte, E.; Sasse, F.; Pawlik, J.R.; Koeck, M. Bioactive metabolites from the caribbean sponge Aka coralliphagum. J. Nat. Prod. 2007, 70, 504-509.

103. Kondracki, M.L.; Guyot, M. Smenospongine: A cytotoxic and antimicrobial aminoquinone isolated from Smenospongia sp. Tetrahedron Lett. 1987, 28, 5815-5818.

104. Kwak, J.H.; Schmitz, F.J.; Kelly, M. Sesquiterpene quinols/quinones from the Micronesian sponge Petrosaspongia metachromia. J. Nat. Prod. 2000, 63, 1153-1156.

105. Aoki, S.; Kong, D.; Matsui, K.; Kobayashi, M. Smenospongine, a spongean sesquiterpene aminoquinone, induces erythroid differentiation in K562 cells. Anticancer Drugs 2004, 15, 363-369. 
106. Aoki, S.; Kong, D.; Matsui, K.; Rachmat, R.; Kobayashi, M. Sesquiterpene aminoquinones, from a marine sponge, induce erythroid differentiation in human chronic myelogenous leukemia, K562 cells. Chem. Pharm. Bull. 2004, 52, 935-937.

107. Ovenden, S.P.B.; Nielson, J.L.; Liptrot, C.H.; Willis, R.H.; Tapiolas, D.M.; Wright, A.D.; Motti, C.A. Sesquiterpene benzoxazoles and sesquiterpene quinones from the marine sponge Dactylospongia elegans. J. Nat. Prod. 2011, 74, 65-68.

108. Augustijns, P.; Annaert, P.; Heylen, P.; van den Mooter, G.; Kinget, R. Drug absorption studies of prodrug esters using the Caco-2 model: Evaluation of ester hydrolysis and transepithelial transport. Int. J. Pharm. 1998, 166, 45-53.

109. Giannini, C.; Debitus, C.; Lucas, R.; Ubeda, A.; Paya, M.; Hooper, J.N.A.; D’Auria, M.V. New sesquiterpene derivatives from the sponge Dysidea species with a selective inhibitor profile against human phospholipase A2 and other leukocyte functions. J. Nat. Prod. 2001, 64, 612-615.

110. Zhang, Y.; Li, Y.; Guo, Y.; Jiang, H.; Shen, X. A sesquiterpene quinone, dysidine, from the sponge Dysidea villosa, activates the insulin pathway through inhibition of PTPases. Acta Pharmacol. Sin. 2009, 30, 333-345.

111. Diaz-Marrero, A.R.; Austin, P.; van Soest, R.; Matainaho, T.; Roskelley, C.D.; Roberge, M.; Andersen, R.J. Avinosol, a meroterpenoid-nucleoside conjugate with antiinvasion activity isolated from the marine sponge Dysidea sp. Org. Lett. 2006, 8, 3749-3752.

112. Rodriguez, A.D.; Yoshida, W.Y.; Scheuer, P.J. Popolohuanone A and B. Two new sesquiterpenoid aminoquinones from Pacific sponge Dysidea sp. Tetrahedron 1990, 46, 8025-8030.

113. Carney, J.R.; Scheuer, P.J. Popolohuanone E, a topoisomerase II inhibitor eith selective lung citotoxicity from Pohnpei sponge Dysidea sp. Tetrahedron Lett. 1993, 34, 3727-3730.

114. Utkina, N.K.; Denisenko, V.A.; Krasokhin, V.B. Sesquiterpenoidd aminoquinones from marine sponge Dysidea sp. J. Nat. Prod. 2010, 73, 788-791.

115. Shigemori, H.; Madono, T.; Sasaki, T.; Mikami, Y.; Kobayashi, J. Nakijiquinones A and B, new antifungal sesquiterpenoid quinones with an amino acid residue from an Okinawan marine sponge. Tetrahedron 1994, 50, 8347-8354.

116. Kobayashi, J.; Madono, T.; Shigemori, H. Nakijiquinones C and D, new sesquiterpenoid quinones with a hydroxy amino acid residue from a marine sponge inhibiting c-erbB-2 kinase. Tetrahedron 1995, 51, 10867-10874.

117. Takahashi, Y.; Kubota, T.; Kobayashi, J. Nakijiquinones E and F, new dimeric sesquiterpenoid quinones from marine sponge. Bioorg. Med. Chem. 2009, 17, 2185-2188.

118. Takahashi, Y.; Kubota, T.; Ito, J.; Mikami, Y.; Fromont, J.; Kobayashi, J. Nakijiquinones G-I, new sesquiterpenoid quinones from marine sponge. Bioorg. Med. Chem. 2008, 16, 7561-7564.

119. Takahashi, Y.; Ushio, M.; Kubota, T.; Yamamoto, S.; Fromont, J.; Kobayashi, J. Nakijiquinones $\mathrm{J}-\mathrm{R}$, sesquiterpenoid quinones with an amine residue from Okinawan marine sponges. J. Nat. Prod. 2010, 73, 467-471.

120. Stahl, P.; Kissau, L.; Mazitschek, R.; Huwe, A.; Furet, P.; Giannis, A.; Waldmann, H. Total synthesis and biological evaluation of the nakijiquinones. J. Am. Chem. Soc. 2001, 123, 11586-11593. 
121. Mitome, H.; Nagasawa, T.; Miyaoka, H.; Yamada, Y.; van Soest, R.W.M. Dactyloquinones A and $\mathrm{B}$, new sesquiterpenoid quinones from the okinawan marine sponge Dactylospongia elegans. J. Nat. Prod. 2001, 64, 1506-1508.

122. Mitome, H.; Nagasawa, T.; Miyaoka, H.; Yamada, Y.; van Soest, R.W.M. Dactyloquinones C, D and E novel sesquiterpenoid quinones, from the Okinawan marine sponge, Dactylospongia elegans. Tetrahedron 2002, 58, 1693-1696.

123. Djura, P.; Stierle, D.B.; Sullivan, B.; Faulkner, D.J.; Arnold, E.V.; Clardy, J. Some metabolites of the marine sponges Smenospongia aurea and Smenospongia (三Polyfibrospongia) echina. J. Org. Chem. 1980, 45, 1435-1441.

124. Wright, A.E.; Rueth, S.A.; Cross, S.S. An antiviral sesquiterpene hydroquinone from the marine sponge Strongylophora hartmani. J. Nat. Prod. 1991, 54, 1108-1111.

125. Cimino, G.; de Stefano, S.; Minale, L. Chromazonarol, a chroman-sesquiterpenoid from sponge Dysidea pallenscens. Experientia 1975, 31, 1117.

126. Barrero, A.J.; Alvarez-Manzaneda, E.J.; Herrador, M.M.; Chahboun, R.; Galera, P. Synthesis and antitumoral activities of marine ent-chromazonarol and related compounds. Bioorg. Med. Chem. Lett. 1999, 9, 2325-2328.

127. Song, F.; Fan, X.; Xu, X.; Wang, S.; Li, S.; Yang, Y.; Shi, J. Studies on chemical constituents of the brown alga Dictyopteris divaricata. Zhongguo Zhong Yao Za Zhi 2006, 31, 125-128.

128. Hideaki, I.; Kazuaki, I.; Hisashi, Y. A new artificial cyclase for poliprenoids: Enantioselective total synthesis of (-)-chromazonarol, (+)-8-epi-puupehedione and (-)-11'-deoxytaondiol methyl ether. J. Am. Chem. Soc. 2004, 126, 11133-11123.

129. Ravi, B.N.; Perzanowski, H.P.; Ross, R.A.; Erdman, T.R.; Scheuer, P.J.; Finer, J.; Clardy, J. Recent research in marine natural products: The puupehenones. Pure Appl. Chem. 1979, 51, 1893-1900.

130. Nasu, S.S.; Yeung, B.K.S.; Hamann, M.T.; Scheuer, P.J.; Kelly-Borges, M.; Goins, K. Puupehenone-related metabolites from two Hawaiian sponges, Hyrtios spp. J. Org. Chem. 1995, 60, 7290-7292.

131. Bourguet-Kondracki, M.L.; Debitus, C.; Guyot, M. Dipuupehedione, a cytotoxic new red dimer from a New Caledonian marine sponge Hyrtios sp. Tetrahedron Lett. 1996, 37, 3861-3864.

132. Bourguet-Kondracki, M.L.; Lacombe, F.; Guyot, M. Methanol adduct of puupehenone, a biologically active derivative from the marine sponge Hyrtios species. J. Nat. Prod. 1999, 62, 1304-1305.

133. Piña, I.C.; Sanders, M.L.; Crews, P. Puupehenone congeners from an Indo-Pacific Hyrtios sponge. J. Nat. Prod. 2003, 66, 2-6.

134. Ciavatta, M.L.; Gresa, M.P.L.; Gavagnin, M.; Romero, V.; Melck, D.; Manzo, E.; Guo, Y.W.; van Soest, R.; Cimino, G. Studies on puupehenone-metabolites of a Dysidea sp.: Structure and biological activity. Tetrahedron 2007, 63, 1380-1384.

135. Robinson, S.J.; Hoobler, E.K.; Riener, M.; Loveridge, S.T.; Tenney, K.; Valeriote, F.A.; Holman, T.R.; Crews, P. Using enzyme assays to evaluate the structure and bioactivity of sponge-derived meroterpenes. J. Nat. Prod. 2009, 72, 1857-1863. 
136. Xu, W.H.; Ding, Y.; Jacob, M.R.; Agarwal, A.K.; Clark, A.M.; Ferreira, D.; Liang, Z.S.; Li, X.C. Puupehanol, a sesquiterpene-dihydroquinone derivative from the marine sponge Hyrtios sp. Bioorg. Med. Chem. Lett. 2009, 19, 6140-6143.

137. Amade, P.; Chevelot, L.; Perzanowski, H.P.; Scheuer, P.J. A dimer of puupehenone. Helv. Chim. Acta 1983, 66, 1672-1675.

138. Castro, M.E.; González-Iriarte, M.; Barrero, A.F.; Salvador-Tormo, N.; Muñoz-Chápuli, R.; Medina, M.A.; Quesada, A.R. Study of puupehenone and related compounds as inhibitors of angiogenesis. Int. J. Cancer 2004, 110, 31-38.

139. El Sayed, K.A.; Bartyzel, P.; Shen, X.; Perry, T.L.; Zjawiony, J.K.; Hamann, M.T. Marine natural products as antituberculosis agents. Tetrahedron 2000, 56, 949-953.

140. Douat-Casassus, C.; Marchand-Geneste, N.; Diez, E.; Aznar, C.; Picard, P.; Geoffre, S.; Huet, A.; Bourguet-Kondracki, M.L.; Gervois, N.; Jotereau, F.; et al. Covalent modification of a melanoma-derived antigenic peptide with a natural quinone methide. Preliminary chemical, molecular modelling and immunological evaluation studies. Mol. BioSyst. 2006, 2, 240-249.

141. Utkina, N.K.; Denisenko, V.A.; Krasokhin, V.B. Diplopuupehenone, a new unsymmetrical puupehenone-related dimer from the marine sponge Dysidea sp. Tetrahedron Lett. 2011, 52, 3765-3768.

142. Quideau, S.; Lebon, M.; Lamidey, A.M. Enantiospecific synthesis of the antituberculosis marine sponge metabolite $(+)$-puupehenone. The arenol oxidative activation route. Org. Lett. 2002, 4, 3975-3978.

143. Chan, J.A.; Freyer, A.J.; Carté, B.K.; Hemling, M.E.; Hofmann, G.H.; Mattern, M.R.; Mentzer, M.A.; Westley, J.W. Protein kinase C inhibitors: Novel spitosequiterpene aldehydes from a marine sponge $A k a$ (=Siphonodictyon) coralliphagum. J. Nat. Prod. 1994, 57, 1543-1548.

144. Utkina, N.K.; Denisenko, V.A.; Scholokova, O.V.; Virovaya, M.V.; Prokof'eva, N.G. Cyclosmenospongine, a new sesquiterpenoid aminoquinone from an Australian marine sponge Spongia sp. Tetrahedron Lett. 2003, 44, 101-102.

145. Utkina, N.K.; Denisenko, V.A.; Scholokova, O.V.; Makarchenko, A.E. Determination of the absolute stereochemistry of cyclosmenospongine. J. Nat. Prod. 2003, 66, 1263-1265.

146. Mitome, H.; Nagasawa, T.; Miyaoka, H.; Yamada, Y.; van Soest, R.W.M. A new sesquiterpenoid quinone and other related compounds from the okinawan marine sponge Dactylospongia elegans. J. Nat. Prod. 2003, 66, 46-50.

147. Killday, K.B.; Wright, A.E. Bis(Sulfato)-cyclosiphonodictyol A, a new disulfated sesquiterpene-hydroquinone from a deep water collection of the marine sponge Siphonodictyon coralliphagum. J. Nat. Prod. 1995, 58, 958-960.

148. Patil, A.D.; Freyer, A.J.; Killmer, L.; Offen, P.; Carte, B.; Jurewicz, A.J.; Johnson, R.K. Frondosins, five new sesquiterpene hydroquinone derivatives with novel skeletons from the sponge Dysidea frondosa: Inhibitors of interleukin-8 receptors. Tetrahedron 1997, 53, 5047-5060.

149. Jiao, W.-H.; Huang, X.-J.; Yang, J.-S.; Yang, F.; Piao, S.-J.; Gao, H.; Li, J.; Ye, W.-C.; Yao, X.; Chen, W.-S.; et al. Dysidavarones A-D, new sesquiterpene quinones from the marine sponge Dysidea avara. Org. Lett. 2012, 14, 202-205. 
150. Nakamura, H.; Kobayashi, J.; Kobayashi, M.; Ohizumi, Y.; Hirata, Y. Xestoquinone. A novel cardiotonic marine natural product isolated from the Okinawan sea sponge Xestospongia sapra. Chem. Lett. 1985, 6, 713-716.

151. Roll, D.M.; Scheuer, P.J. Halenaquinone, a pentacyclic polyketide from a marine sponge. J. Am. Chem. Soc. 1983, 105, 6177-6178.

152. Cao, S.; Foster, C.; Brisson, M.; Lazo, J.S.; Kingston, D.G.I. Halenaquinone and xestoquinone derivatives, inhibitors of Cdc25B phosphatase from a Xestospongia sp. Bioorg. Med. Chem. 2005, 13, 999-1003.

153. Concepcion, G.P.; Foderaro, T.A.; Eldredge, G.S.; Lobkovsky, E.; Clardy, J.; Barrows, L.R.; Ireland, C.M. Topoisomerase II-mediated DNA Cleavage by adocia- and xestoquinones from the philippine sponge Xestospongia sp. J. Med. Chem. 1995, 38, 4503-4507.

154. Schmitz, F.J.; Bloor, S.J. Xesto- and halenaquinone derivatives from a sponge, Adocia sp., from truk lagoon. J. Org. Chem. 1988, 53, 3922-3925.

155. Desoubzdanne, D.; Marcourt, L.; Raux, R.; Chevalley, S.; Dorin, D.; Doerig, C.; Valentin, A.; Ausseil, F.; Debitus, C. Alisiaquinones and alisiaquinol, dual inhibitors of plasmodium falciparum enzyme targets from a new caledonian deep water sponge. J. Nat. Prod. 2008, 71, 1189-1192.

156. Zhang, H.; Khalil, Z.G.; Capon, R.J. Fascioquinols A-F: Bioactive meroterpenes from a deep-water southern Australian marine sponge Fasciospongia sp. Tetrahedron 2011, 67, 2591-2595.

157. Standish, A.J.; Salim, A.A.; Zhang, H.; Capon, R.J.; Morona, R. Chemical inhibition of bacterial protein tyrosine phosphatase suppresses capsule production. PLoS One 2012, 7, e36312.

158. Standish, A.J.; Salim, A.A.; Capon, R.J.; Morona, R. Dual inhibition of DNA polymerase PolC and protein tyrosine phosphatase $\mathrm{CpsB}$ uncovers a novel antibiotic target. Biochem. Biophys. Res. Commun. 2013, 430, 167-172.

159. Tasdemir, D.; Concepción, G.P.; Mangalindan, G.C.; Harper, M.K.; Hajduc, E.; Ireland, C.M. New terpenoids from a Cacospongia sp. from the Philippines. Tetrahedron 2000, 56, 9025-9030.

160. Murray, L.M.; Johnson, A.; Diaz, M.C.; Crews, P. Geographic variation in the tropical marine sponge Jaspis cf. johnstoni: An unexpected source of new terpene-benzenoids. J. Org. Chem. 1997, 62, 5638-5641.

161. Rubio, B.K.; van Soest, R.W.M.; Crews, P. Extending the record of meroditerpenes from Cacospongia marine sponges. J. Nat. Prod. 2007, 70, 628-631.

162. Loll, P.J.; Axelsen, P.H. The structural biology of molecular recognition by vancomycin. Annu. Rev. Biophys. Biomol. Struct. 2000, 29, 265-289.

163. Carroll, J.; Jonsson, E.N.; Ebel, R.; Hartman, M.S.; Holman, T.R.; Crews, P. Probing sponge-derived terpenoids for human 15-lipoxygenase inhibitors. J. Org. Chem. 2001, 66, 6847-6851.

164. Williams, D.E.; Telliez, J.B.; Liu, J.; Tahir, A.; van Soest, R.; Andersen, R.J. Meroterpenoid MAPKAP (MK2) inhibitors isolated from the Indonesian marine sponge Acanthodendrilla sp. J. Nat. Prod. 2004, 67, 2127-2129. 
165. Cichewicz, R.H.; Kenyon, V.A.; Whitman, S.; Morales, N.M.; Arguello, J.F.; Holman, T.R.; Crews, P. Redox inactivation of human 15-lipoxygenase by marine-derived meroditerpenes and synthetic chromanes: Archetypes for a unique class of selective and recyclable inhibitors. J. Am. Chem. Soc. 2004, 126, 14910-14920.

166. Braekman, J.C.; Daloze, D.; Hulot, G.; Tursch, B.; Declercq, J.P.; Germain, G.; van Meerssche, M. Chemical studies of marine invertebrates. XXXVII. Three novel meroditerpenoids from the sponge Strongylophora durissima. Bull. Soc. Chim. Belg. 1978, 87, 917-926.

167. Salva, J.; Faulkner, D.J. Metabolites of the sponge Strongylophora durissima from Maricaban Island, Philippines. J. Org. Chem. 1990, 55, 1941-1943.

168. Balbin-Oliveros, M.; Edrada, R.; Proksch, P.; Wray, V.; Witte, W.M.; van Soest, R.W.M. A new meroditerpenoid dimer from an undescribed Philippine marine sponge of the genus Strongylophora. J. Nat. Prod. 1998, 61, 948-952.

169. Liu, H.; Namikoshi, M.; Akano, K.; Kobayashi, H.; Nagai, H.; Yao, X. Seven new meroditerpenoids, from the marine sponge Strongylophora strongylata, that inhibited the maturation of starfish oocytes. J. Asian Nat. Prod. Res. 2005, 7, 661-670.

170. Warabi, K.; Patrick, B.O.; Austin, P.; Roskelley, C.D.; Roberge, M.; Andersen, R.J. Strongylophorine-26, an inhibitor of cancer cell invasion: SAR revealed by synthesis of analogues. J. Nat. Prod. 2007, 70, 736-740.

171. McHardy, L.M.; Warabi, K.; Andersen, R.J.; Roskelley, C.D.; Roberge, M. Strongylophorine-26, a Rho-dependent inhibitor of tumor cell invasion that reduces actin stress fibers and induces nonpolarized lamellipodial extensions. Mol. Cancer Ther. 2005, 4, 772-778.

172. Shen, Y.C.; Prakash, C.V. Two new acetylenic derivatives and a new meroditerpenoid from a Taiwanese marine sponge Strongylophora durissima. J. Nat. Prod. 2000, 63, 1686-1688.

173. Warabi, K.; McHardy, L.M.; Matainaho, L.; van Soest, R.W.M.; Roskelley, C.D.; Roberge, M.; Andersen, R.J. Strongylophorine-26, a new meroditerpenoid isolated from the marine sponge Petrosia (Strongylophora) corticata that exhibits anti-invasion activity. J. Nat. Prod. 2004, 67, 1387-1389.

174. Mohammed, K.A.; Jadulco, R.C.; Bugni, T.S.; Harper, M.K.; Sturdy, M.; Ireland, C.M.; Strongylophorines: Natural product inhibitors of hypoxia-inducible factor-1 transcriptional pathway. J. Med. Chem. 2008, 51, 1402-1405.

175. Sasaki, S.; Tozawa, T.; van Wagoner, R.M.; Ireland, C.M.; Harper, M.K.; Satoh, T. Strongylophorine-8, a pro-electrophilic compound from the marine sponge Petrosia (Strongylophora) corticata, provides neuroprotection through Nrf2/ARE pathway. Biochem. Biophys. Res. Commun. 2011, 415, 6-10.

176. Bae, J.M.; Jeon, J.E.; Lee, Y.J.; Lee, H.S.; Sim, C.J.; Oh, K.B.; Shin, J.H. Sesterterpenes from the tropical sponge Coscinoderma sp. J. Nat. Prod. 2011, 74, 1805-1811.

177. Alea, G.V.; Carroll, A.R.; Bowden, B.F. Coscinoquinol, a new cytotoxic sesterterpene from a dictyoceratid sponge, Coscinoderma sp. Aust. J. Chem. 1994, 47, 191-194.

178. Kernan, M.R.; Faulkner, D.J. Sesterterpene sulfates from a sponge of the family Halichondriidae. J. Org. Chem. 1988, 53, 4574-4578. 
179. Loukaci, A.; Le Saout, I.; Samadi, M.; Leclerc, S.; Damiens, E.; Meijer, L.; Debitus, C.; Guyot, M. Coscinosulfate, a CDC25 phosphatase inhibitor from the sponge Coscinoderma mathewsi. Bioorg. Med. Chem. 2001, 9, 3049-3054.

180. Kimura, J.; Ishizuka, E.; Nakao, Y.; Yoshida, W.Y.; Scheuer, P.J.; Kelly-Borges, M. Isolation of 1-methylherbipoline salts of halisulfate-1 and of suvanine as serine protease inhibitors from a marine sponge, Coscinoderma mathewsi. J. Nat. Prod. 1998, 61, 248-250.

181. Lee, H.S.; Lee, T.H.; Yang, S.H.; Shin, H.J.; Shin, J.; Oh, K.B. Sesterterpene sulfates as isocitrate lyase inhibitors from tropical sponge Hippospongia sp. Bioorg. Med. Chem. Lett. 2007, 17, 2483-2486.

182. Shin, D.S.; Lee, T.H.; Lee, H.S.; Shin, J.; Oh, K.B. Inhibition of infection of the rice blast fungus by halisulfate 1, an isocitrate lyase inhibitor. FEMS Microbiol. Lett. 2007, 272, 43-47.

183. De Marino, S.; Festa, C.; D’Auria, M.V.; Bourguet-Kondracki, M.-L.; Petek, S.; Debitus, C.; Andres, R.M.; Terencio, M.C.; Paya, M.; Zampella, A. Coscinolactams A and B: New nitrogen-containing sesterterpenoids from the marine sponge Coscinoderma mathewsi exerting anti-inflammatory properties. Tetrahedron 2009, 65, 2905-2909.

184. Baratte, B.; Meijer, L.; Galaktionov, K.; Beach, D. Screening for antimitotic compounds using the cdc25 tyrosine phosphatase, an activator of the mitosis-inducing $\mathrm{p} 34 \mathrm{cdc} 2 /$ cyclin Bcdc13 protein kinase. Anticancer Res. 1992, 12, 873-880.

185. Isaacs, S.; Kashman, Y. Shaagrockol B and C; two hexaprenylhydroquinone disulfates from the Red Sea sponge Toxiclona toxius. Tetrahedron Lett. 1992, 33, 2227-2230.

186. Isaacs, S.; Hizi, A.; Kashman, Y. Toxicols A-C and toxiusol-New bioactive hexaprenoid hydroquinones from Toxiclona toxius. Tetrahedron 1993, 49, 4275-4282.

187. Blackburn, C.L.; Hopmann, C.; Sakowicz, R.; Berdelis, M.S.; Goldstein, L.S.B.; Faulkner, D.J. Adociasulfates 1-6, inhibitors of kinesin motor proteins from the sponge Haliclona (aka Adocia) sp. J. Org. Chem. 1999, 64, 5565-5570.

188. Blackburn, C.L.; Faulkner, D.J. Adociasulfate 10, a new merohexaprenoid sulfate from the sponge Haliclona (aka Adocia) sp. Tetrahedron 2000, 56, 8429-8432.

189. Kalaitzis, J.A.; Leone, P.A.; Harris, L.; Butler, M.S.; Ngo, A.; Hooper, J.N.A.; Quinn, R.J. Adociasulfates 1, 7, and 8: New bioactive hexaprenoid hydroquinones from the marine sponge Adocia sp. J. Org. Chem. 1999, 64, 5571-5574.

190. West, L.M.; Faulkner, D.J. Hexaprenoid hydroquinones from the sponge Haliclona (aka Adocia) sp. J. Nat. Prod. 2006, 69, 1001-1004.

191. Kalaitzis, J.A.; Quinn, R.J. Adociasulfate-9, a new hexaprenoid hydroquinone from the Great Barrier Reef sponge Adocia aculeata. J. Nat. Prod. 1999, 62, 1682-1684.

192. Barton, N.R.; Goldstein, L.S.B. Going mobile: Microtubule motors and chromosome segregation. Proc. Natl. Acad. Sci. USA 1996, 93, 1735-1742.

193. Hirokawa, N. Kinesin and dynein superfamily proteins and the mechanism of organelle transport. Science 1998, 279, 519-526.

194. Crews, P.; Harrison, B. New triterpene-ketides (merotriterpenes), haliclotriol A and B, from an indo-pacific Haliclona sponge. Tetrahedron 2000, 56, 9039-9046.

195. Trianto, A.; Hermawan, I.; de Voogd, N.J.; Tanaka, J. Halioxepine, a new meroditerpene from an Indonesian sponge Haliclona sp. Chem. Pharm. Bull. 2011, 59, 1311-1313. 
196. Fisch, K.M.; Böhm, V.; Wright, A.D.; König, G.M. Antioxidative meroterpenoids from the brown alga Cystoseira crinite. J. Nat. Prod. 2003, 66, 968-975.

197. Williams, D.E.; Steinø, A.; de Voogd, N.J.; Mauk, A.G.; Andersen, R.J. Halicloic acids A and B isolated from the marine sponge Haliclona sp. collected in the Philippines inhibit indoleamine 2,3-dioxygenase. J. Nat. Prod. 2012, 75, 1451-1458.

198. Fukami, A.; Ikeda, Y.; Kondo, S.; Naganawa, H.; Takeuchi, T.; Furuya, S.; Hirabayashi, Y.; Shimoike, K.; Hosaka, S.; Watanabe Y.; Umezawa, K. Akaterpin, a novel bioactive triterpene from the marine sponge Callyspongia sp. Tetrahedron Lett. 1997, 38, 1201-1202.

199. Gray, C.A.; de Lira, S.P.; Silva, M.; Pimenta, E.F.; Thiemann, O.H.; Oliva, G.; Hajdu, E.; Andersen, R.J.; Berlinck, R.G.S. Sulfated meroterpenoids from the Brazilian sponge Callyspongia sp. are inhibitors of the antileishmaniasis target adenosine phosphoribosyl transferase. J. Org. Chem. 2006, 71, 8685-8690.

200. Hooper, G.J.; Davies-Coleman, M.T. Sesquiterpene hydroquinones from the South African soft coral Alcyonium fauri. Tetrahedron Lett. 1995, 36, 3265-3268.

201. Sheu, J.H.; Su, J.H.; Sung, P.J.; Wang, G.H.; Dai, C.F. Novel meroditerpenoid-related metabolites from the formosan soft coral Nephthea chabrolii. J. Nat. Prod. 2004, 67, 2048-2052.

202. Su, J.H.; Ahmed, A.F.; Sung, P.J.; Wu, Y.C.; Sheu, J.H. Terpenoid-related metabolites from a formosan soft coral Nephthea Chabrolii. J. Nat. Prod. 2005, 68, 1651-1655.

203. Su, J.H.; Dai, C.F.; Huang, H.H.; Wu, Y.C.; Sung, P.J.; Hsu, C.H.; Sheu, J.H. Terpenoid-related metabolites from a Formosan soft coral Nephthea chabrolii. Chem. Pharm. Bull. 2007, 55, 594-597.

204. Chen, J.W.; Luo, Y.L.; Hwang, M.J.; Peng, F.C.; Ling, K.H.J. Territrem B, a tremorgenic mycotoxin that inhibits acetylcholinesterase with a noncovalent yet irreversible binding mechanism. Biol. Chem. 1999, 274, 34916-34923.

205. Cueto, M.; MacMillan, J.B.; Jensen, P.R.; Fenical, W. Tropolactones A-D, four meroterpenoids from a marine-derived fungus of the genus Aspergillus. Phytochemistry 2006, 67, 1826-1831.

206. Cohen, E.; Koch, L.; Myint Thu, K.; Rahamim, Y.; Aluma, Y.; Ilan, M.; Yarden, O.; Carmeli, S. Novel terpenoids of the fungus Aspergillus insuetus isolated from the Mediterranean sponge Psammocinia sp. collected along the coast of Israel. Bioorg. Med. Chem. 2011, 19, 6587-6593.

207. Lopez-Gresa, M.P.; Cabedo, N.; Gonzalez-Mas, M.C.; Ciavatta, M.L.; Avila, C.; Primo, J. Terretonins $\mathrm{E}$ and $\mathrm{F}$, inhibitors of the mitochondrial respiratory chain from the marine-derived fungus Aspergillus insuetus. J. Nat. Prod. 2009, 72, 1348-1351.

208. Zhou, Y.; Mándi, A.; Debbab, A.; Wray, V.; Schulz, B.; Müller, W.E.G.; Lin, W.H.; Proksch, P.; Kurtán, T.; Aly, A.H. New austalides from the sponge-associated fungus Aspergillus sp. Eur. J. Org. Chem. 2011, 2011, 6009-6019.

209. Bugni, T.S.; Abbanat, D.; Bernan, V.S.; Malese, W.M.; Greenstein, M.; van Wagoner, R.; Ireland, C.M. Yanuthones: Novel metabolites from a marine isolate of Aspergillus niger. J. Org. Chem. 2000, 65, 7195-7200.

210. Sanchez, J.F.; Somoza, A.D.; Kellerc, N.P.; Wang, C.C.C. Advances in Aspergillus secondary metabolite research in the post-genomic era. Nat. Prod. Rep. 2012, 29, 351-371. 
211. Lo, H.; Entwistle, R.; Guo, C.; Ahuja, M.; Szewczyk, E.; Hung, J.; Chiang, Y.; Oakley, B.R.; Wang, C.C.C. Two separate gene clusters encode the biosynthetic pathway for the meroterpenoids austinol and dehydroaustinol in Aspergillus nidulans. J. Am. Chem. Soc. 2012, 134, 4709-4720.

212. Guo, C.; Knox, B.P.; Chiang, Y.; Lo, H.; Sanchez, J.F.; Lee, K.; Oakley, B.R.; Bruno, K.S.; Wang, C.C.C. Molecular genetic characterization of a cluster in A. terreus for biosynthesis of the meroterpenoid Terretonin. Org. Lett. 2012, 14, 5684-5687.

(C) 2013 by the authors; licensee MDPI, Basel, Switzerland. This article is an open access article distributed under the terms and conditions of the Creative Commons Attribution license (http://creativecommons.org/licenses/by/3.0/). 